\title{
๖The Diurnal Cycle of Precipitation according to Multiple Decades of Global Satellite Observations, Three CMIP6 Models, and the ECMWF Reanalysis $\mathscr{O}$
}

\author{
Daniel Watters,${ }^{\mathrm{a}, \mathrm{b}}$ Alessandro Battaglia,${ }^{\mathrm{a}, \mathrm{b}, \mathrm{c}}$ And Richard P. Allan ${ }^{\mathrm{d}, \mathrm{e}}$ \\ ${ }^{a}$ Earth Observation Science Group, Department of Physics and Astronomy, Leicester, United Kingdom \\ ${ }^{\mathrm{b}}$ National Centre for Earth Observation, University of Leicester, Leicester, United Kingdom \\ ${ }^{\mathrm{c}}$ DIATI, Politecnico di Torino, Turin, Italy \\ ${ }^{\mathrm{d}}$ Department of Meteorology, University of Reading, Reading, United Kingdom \\ ${ }^{\mathrm{e}}$ National Centre for Earth Observation, University of Reading, Reading, United Kingdom
}

(Manuscript received 15 December 2020, in final form 16 March 2021)

\begin{abstract}
NASA Precipitation Measurement Mission observations are used to evaluate the diurnal cycle of precipitation from three CMIP6 models (NCAR-CESM2, CNRM-CM6.1, CNRM-ESM2.1) and the ERA5 reanalysis. NASA's global-gridded IMERG product, which combines spaceborne microwave radiometer, infrared sensor, and ground-based gauge measurements, provides high-spatiotemporal-resolution $\left(0.1^{\circ}\right.$ and half-hourly) estimates that are suitable for evaluating the diurnal cycle in models, as determined against the ground-based radar network over the conterminous United States. IMERG estimates are coarsened to the spatial and hourly resolution of the state-of-the-art CMIP6 and ERA5 products, and their diurnal cycles are compared across multiple decades of June-August in the $60^{\circ} \mathrm{N}-60^{\circ} \mathrm{S}$ domain (IMERG and ERA5: 2000-19; NCAR and CNRM: 1979-2008). Low-precipitation regions (and weak-amplitude regions when analyzing the diurnal phase) are excluded from analyses so as to assess only robust diurnal signals. Observations identify greater diurnal amplitudes over land $(26 \%-134 \%$ of the precipitation mean; 5 th- 95 th percentile) than over ocean $(14 \%-$ $66 \%)$. ERA5, NCAR, and CNRM underestimate amplitudes over ocean, and ERA5 overestimates over land. IMERG observes a distinct diurnal cycle only in certain regions, with precipitation peaking broadly between 1400 and 2100 LST over land (2100-0600 LST over mountainous and varying-terrain regions) and 0000 and 1200 LST over ocean. The simulated diurnal cycle is unrealistically early when compared with observations, particularly over land (NCAR-CESM2 AMIP: $-1 \mathrm{~h}$; ERA5: $-2 \mathrm{~h}$; CNRM-CM6.1 AMIP: $-4 \mathrm{~h}$ on average) with nocturnal maxima not well represented over mountainous regions. Furthermore, ERA5's representation of the diurnal cycle is too simplified, with less interannual variability in the time of maximum relative to observations over many regions.
\end{abstract}

SIGNIFICANCE STATEMENT: Identifying and addressing climate model errors in representing the diurnal cycle of precipitation are critical to improving their accuracy. This study provides an update on the diurnal cycle performance of state-of-the-art climate models and reanalysis against state-of-the-art satellite observations. The models and reanalysis have varying biases in diurnal amplitude over land, where amplitudes are stronger, and they underestimate amplitudes over ocean. They also simulate precipitation over land to peak too early in the day, from -1 to $-4 \mathrm{~h}$ on average depending on the model. Nocturnal maxima in mountainous regions are not well simulated, although the reanalysis outperforms the models in this case. Future work can use these findings to improve realism in the next generation of climate models.

KEYWORDS: Precipitation; Microwave observations; Radars/radar observations; Remote sensing; Satellite observations; Climate models; Diurnal effects

\section{Introduction}

Precipitation is a critical component of the climate system; it intertwines the energy budget and the water cycle via its link to

\footnotetext{
๑ Denotes content that is immediately available upon publication as open access.
}

Supplemental information related to this paper is available at the Journals Online website: https://doi.org/10.1175/JCLI-D-200966.s1.

Corresponding authors: Daniel Watters, dcw17@leicester.ac.uk; Alessandro Battaglia, ab474@leicester.ac.uk latent heat flux (Stephens et al. 2012), impacts upon society (by causation of flooding, famine, and freshwater availability), and is expected to increase globally with warming of Earth, particularly within regions of moisture convergence (Allan et al. 2020). Precipitation is one of the most challenging variables to represent in simulations since they must capture its high spatiotemporal variability, which is determined by multiple factors including longwave and shortwave radiation, convection, humidity, and precipitation microphysics (Tapiador et al. 2019). Climate models have struggled with accurately representing precipitation,

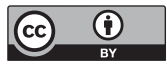

This article is licensed under a Creative Commons Attribution 4.0 license (http://creativecommons.org/ licenses/by/4.0/). 
with precipitation occurring too often, too lightly (Chen et al. 1996; Stephens et al. 2010; Trenberth et al. 2017), and too early in the day (Dai et al. 1999; Dai and Trenberth 2004; Dai 2006; Trenberth et al. 2003; DeMott et al. 2007). Evaluating and addressing long-standing and systematic errors in the diurnal cycle of precipitation are central to improving the realism of the models used to make future climate projections (Eyring et al. 2016).

Observational studies have determined key features of the diurnal cycle across the globe: the diurnal cycle is stronger over land than over ocean, with precipitation typically peaking from midafternoon to evening over land and in the morning over the ocean (Janowiak et al. 1994; Dai 2001, 2006; Dai and Trenberth 2004; Dai et al. 2007; Yang and Slingo 2001; Nesbitt and Zipser 2003; Liu and Zipser 2008; Kikuchi and Wang 2008; Kidd et al. 2013; Covey et al. 2016; Watters and Battaglia 2019; Battaglia et al. 2020a; Minobe et al. 2020). Furthermore, the diurnal amplitude over land is stronger in summer than in winter (Wallace 1975; Dai et al. 1999, 2007; Dai 2006; Yang and Slingo 2001; Kikuchi and Wang 2008; Watters and Battaglia 2019; Battaglia et al. 2020a), and the diurnal cycle of precipitation accumulation is driven by its occurrence instead of its intensity (Dai et al. 1999, 2007; Watters and Battaglia 2019). Some studies have identified that weather and climate models simulate the time of maximum earlier than observed (Yang and Slingo 2001; Betts and Jakob 2002; Trenberth et al. 2003; Dai and Trenberth 2004; Dai 2006; Dirmeyer et al. 2012; Kidd et al. 2013; Flato et al. 2014; Rosa and Collins 2013; Covey et al. 2016). In convection-parameterized coupled climate models, this early diurnal peak in warm-season precipitation over land may be related to the premature onset of cumulus convection, while their weak diurnal oceanic amplitudes may be related to a lack of diurnal variations in their simulated sea surface temperatures (Dai and Trenberth 2004). Convectionpermitting models appear to better represent diurnal phase than convection-parameterized models (Dirmeyer et al. 2012; Scaff et al. 2020), with some skill in capturing nocturnal precipitation peaks in mountainous regions, though they tend to overestimate mean precipitation and diurnal amplitude (Dirmeyer et al. 2012). Furthermore, turning off the parameterized convection scheme is central to improving the diurnal cycle representation rather than increasing horizontal resolution (Pearson et al. 2014). Some studies have evaluated the performance of the preceding phases of CMIP global climate models, with CMIP3 and CMIP5 simulations of diurnal precipitation amplitudes generally identified to be realistic, while their precipitation typically peaks several hours earlier than surface and satellite observations (Dai 2006; Randall et al. 2007; Rosa and Collins 2013; Flato et al. 2014; Covey et al. 2016). The latest CMIP6 multidecade model simulations are yet to be analyzed.

Satellite constellations are capable of observing the diurnal cycle of precipitation across the globe, due to their consistent coverage, fine spatiotemporal sampling, and access to remote areas. Globalgridded products generated from passive microwave (PMW) radiometers and infrared (IR) sensors, with calibration to spaceborne radar and ground-based gauges, are commonly used in global diurnal cycle assessments (e.g., Dai 2006; Dai et al. 2007; Covey et al. 2016; Watters and Battaglia 2019; Battaglia et al. 2020a, etc.), including: the Tropical Rainfall Measuring Mission (TRMM)
Multisatellite Precipitation Analysis (TMPA/3B42; Huffman et al. 2007), and the successor Global Precipitation Measurement (GPM) mission's Integrated Multisatellite Retrievals for GPM (IMERG; Huffman et al. 2019b). IMERG advances upon TMPA by providing extended spatial coverage [IMERG: $90^{\circ} \mathrm{N}-\mathrm{S}$ (partial coverage for $60^{\circ}-90^{\circ} \mathrm{N} / \mathrm{S}$ ); TMPA: $50^{\circ} \mathrm{N}-\mathrm{S}$ ] at finer spatiotemporal resolution (IMERG: $0.1^{\circ} \times 0.1^{\circ}$, half-hourly; TMPA: $0.25^{\circ} \times 0.25^{\circ}, 3$-hourly), and now incorporates measurements from the TRMM era to provide a $20-y r+$ record of precipitation.

The present study evaluates the diurnal cycle of precipitation accumulation for boreal summer from the state-of-the-art IMERG observation, CMIP6 (NCAR and CNRM) model and ECMWF Reanalysis (ERA5; Hersbach et al. 2020) products. Novelties for a global precipitation diurnal cycle study include: the first multidecade analysis with IMERG; the first multidecade evaluation of CMIP6's NCAR and CNRM models and their different simulations; the first global evaluation of ERA5; the first model and reanalysis assessment at the hourly scale; and the first interannual variability investigation. IMERG's capability to reliably represent the diurnal cycle has been demonstrated (Watters and Battaglia 2019; Sungmin and Kirstetter 2018; Tan et al. 2019a; Dezfuli et al. 2017; Tang et al. 2020) and is considered to be a global reference in this study. First, the diurnal cycle from IMERG, NCAR, CNRM, and ERA5 over the conterminous United States (CONUS) and the Gulf Stream is analyzed and validated against the regional reference Multi-Radar Multi-Sensor (MRMS) gauge-adjusted ground-based radar network product; MRMS's radars provide direct near-surface precipitation estimates unlike IMERG's PMW and IR sensors, though are limited to CONUS coverage only. The capability of the GPM Core Observatory's (CO) Dual-Frequency Precipitation Radar (DPR) in capturing the diurnal cycle evolution over CONUS is also investigated. Second, IMERG, NCAR, CNRM, and ERA5 representation of diurnal precipitation mean, normalized amplitude, and time of maximum across the globe are compared. The interannual variability of these diurnal precipitation parameters is investigated.

\section{Data}

The products assessed in this diurnal cycle study are listed in Table 1.

\section{a. Observations}

\section{1) IMERG}

IMERG is the flagship product of the NASA-JAXA GPM mission (Hou et al. 2014; Skofronick-Jackson et al. 2017; Kidd et al. 2020; Watters and Battaglia 2020a). The IMERG algorithm intercalibrates, merges, and interpolates precipitation estimates from the GPM satellite constellation of PMW radiometers in low-Earth orbits, with integration of estimates from geostationary spaceborne IR sensors in PMW-sparse regions, to produce a global-gridded product at $0.1^{\circ}$ and 30 -min resolution (Huffman et al. 2019b, 2020b). The PMW precipitation estimates (Kummerow et al. 2015; Kidd 2019) are seasonally calibrated to the constellation-reference GPM-CO combined radar and PMW radiometer (CORRA) estimates (Olson 2018; 
TABLE 1. List of data products used for the diurnal cycle analysis. For the CMIP6 models, only one simulation variant is used: r1i1p1f2 for the CNRM simulations, r10i1p1f1 for the NCAR-CESM2 AMIP simulation, and r11i1p1f1 for the NCAR-CESM2 Historical simulation.

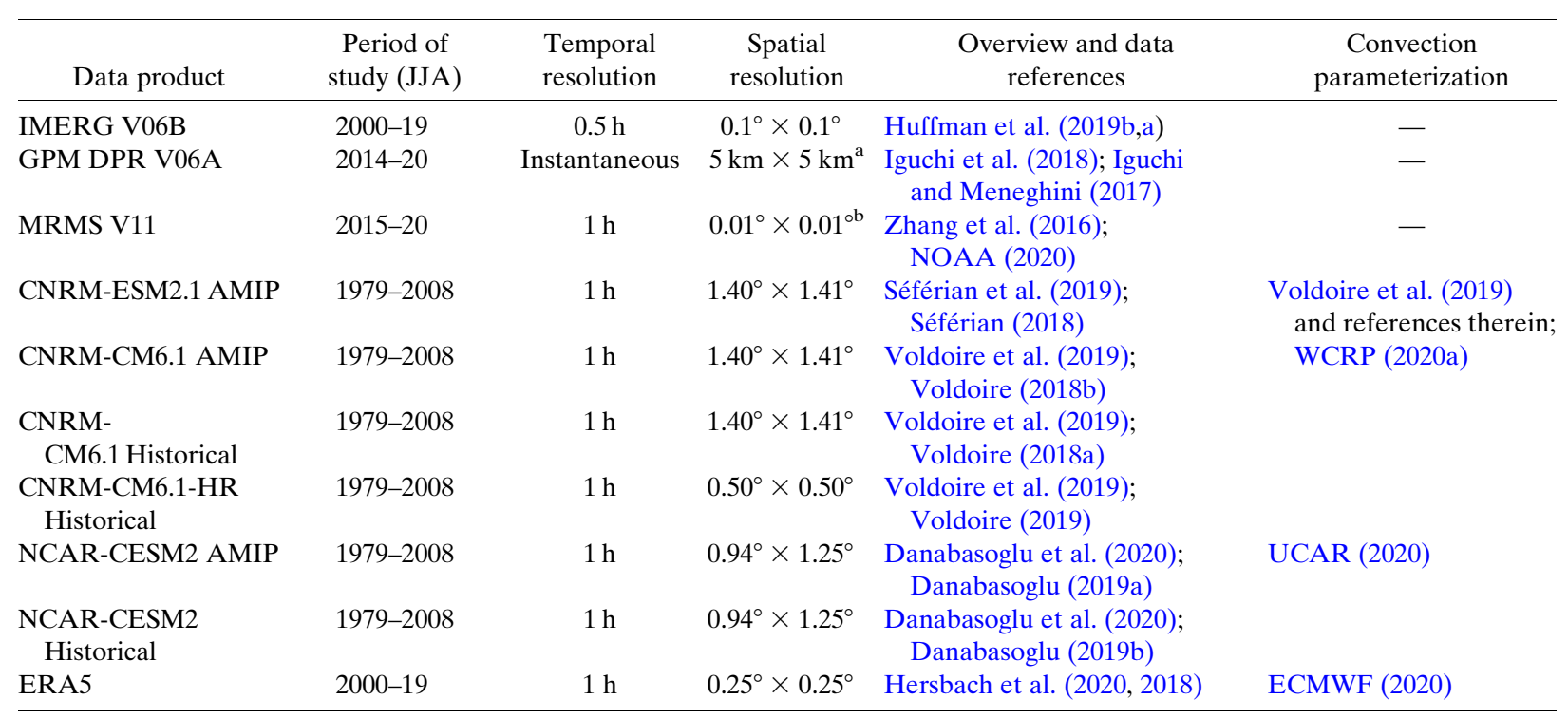

${ }^{a}$ GPM DPR is a satellite granule product with a $120-\mathrm{km}$ swath for dual-frequency matched scan estimates. The GPM Core Observatory (with the DPR on board) overpasses CONUS approximately 4 times per day.

${ }^{\mathrm{b}}$ MRMS only covers CONUS. All other products are global gridded.

Skofronick-Jackson et al. 2018); further climatological calibration to the Global Precipitation Climatology Project (GPCP), version 2.3, monthly satellite-gauge estimates (Adler et al. 2018) is applied where CORRA is biased (low over highlatitude oceans and high over tropical and midlatitude land; Huffman et al. 2020a). The algorithm enhances PMW coverage by propagating precipitation features using a quasi-Lagrangian interpolation scheme (known as morphing; Tan et al. 2019b; Joyce and Xie 2011), before integrating PMW-calibrated IR precipitation estimates (Hong et al. 2004) into PMW-sparse regions between $60^{\circ} \mathrm{N}$ and $60^{\circ} \mathrm{S}$. This study uses IMERG V06B Final Run precipitationCal data, where the PMW-IR estimates are calibrated to monthly Global Precipitation Climatology Centre (GPCC) gauge analyses (Schneider et al. 2014) over land. IMERG V06B now extends back from the GPM era (from June 2014 to the present) into the TRMM era (from June 2000 to May 2014), in which the TRMM satellite's radar and radiometer (Simpson et al. 1996; Kummerow et al. 1998) are the constellation reference; the advancements of the GPM-CO beyond the TRMM satellite (including midlatitude coverage, dual-frequency radar, etc.) are described by Iguchi et al. (2018).

This study uses IMERG as a global reference for the diurnal cycle due to its climatological/monthly calibration to gaugebased products (GPCP, GPCC; reducing biases in diurnal precipitation means), use of the intercalibrated GPM constellation (Berg et al. 2016), and skill in capturing the diurnal cycle over CONUS (Sungmin and Kirstetter 2018; Tan et al. 2019b), Africa (Dezfuli et al. 2017), and China (Tang et al. 2020). IMERG tends to observe the time of maximum precipitation less than $1 \mathrm{~h}$ after MRMS over central and southeastern CONUS (due to PMW sensors measuring hydrometeors at the ice-scattering level; Tan et al. 2019a), and better captures the African diurnal cycle compared to commonly used, modelevaluator TMPA (Dezfuli et al. 2017; Kidd et al. 2013; Covey et al. 2016). Furthermore, IMERG captures the time of maximum, diurnal precipitation range and diurnal standard deviation from rain gauges across China, unlike ERA5 (Tang et al. 2020). However, IMERG is not without bias, with diurnal amplitudes overestimated over central CONUS (Sungmin and Kirstetter 2018) and underestimated over mountainous regions and southeastern CONUS (Sungmin and Kirstetter 2018; Tan et al. 2019a); furthermore, IMERG observes diurnal phase earlier than MRMS for dissipating mesoscale convective systems (MCSs), due to the heightened sensitivity of IMERG's PMW sensors to their convective regions (Sungmin and Kirstetter 2018). Further IMERG biases include systematic overestimation of drizzle and underestimation of heavy/ convective precipitation (Tan et al. 2016; Kirstetter et al. 2020; Maranan et al. 2020), underestimation in mountainous regions (Ramsauer et al. 2018; Navarro et al. 2019; Tapiador et al. 2020) and of snowfall (Tang et al. 2020), and poor performance in coastal regions (Navarro et al. 2019; Tapiador et al. 2020). Southern Ocean anomalies have also been identified $\left(45^{\circ}-60^{\circ} \mathrm{S}\right.$; Watters and Battaglia 2019, 2020b). IMERG performance can also differ by satellite source (Tan et al. 2016), as PMW radiometers are sensitive to precipitation in the column (Watters and Battaglia 2020a), unlike IR sensors, which can only sense the cloud top. While IR retrievals have less skill in representing precipitation than PMW retrievals (with systematic IR underestimates across most precipitation regimes; Kirstetter et al. 2020; Petersen et al. 2020), their contribution to IMERG is less than for predecessor TMPA due 
to its inclusion of a PMW morphing scheme (Tan et al. 2019b). IMERG's morphing scheme and enhanced PMW contribution have also resulted in reduced lags in the time of maximum surface precipitation over CONUS compared to TMPA (Tan et al. 2019a), which along with other PMW-IR products have lagged surface precipitation by a few hours due to each sensor's measurements aloft (Dai et al. 2007).

\section{2) GPM DPR}

The DPR instrument on board the GPM-CO is the only precipitation radar currently in space (Iguchi 2020). It measures the three-dimensional structure of precipitation at $\mathrm{Ku}$ and Ka-band frequencies, with a footprint diameter of $5 \mathrm{~km}$ at nadir from an altitude of $407 \mathrm{~km}$ and a vertical resolution of $250 \mathrm{~m}$. The Ku-band measurements cover a swath of $245 \mathrm{~km}$ centered on the satellite ground track, whereas the Ka-band measurements coincidentally cover the central 120-km region; the Ka-band swath was extended to $245 \mathrm{~km}$ on 21 May 2018 (Iguchi et al. 2018; Iguchi 2020). Only precipitation estimates from the central $120-\mathrm{km}$ swath, where coincident $\mathrm{Ku}$ - and $\mathrm{Ka}$ band measurements are continuously available, are used in this study. The GPM-CO's sun-asynchronous orbit enables DPR precipitation estimates throughout all local times.

This study uses the DPR V06A product's estimated surface precipitation rate (precipRateESurface), produced using the dual-frequency retrieval. This retrieval converts the rangeresolved $\mathrm{Ku}$-band and $\mathrm{Ka}$-band received power into measured radar reflectivity factors, corrects for the signal attenuation due to clouds, and applies assumptions on the precipitation size distribution to determine precipitation rates (Iguchi et al. 2018; Iguchi 2020); coincident measurements at two different frequencies enables better constraint of the precipitation size distribution, which in turn improves the precipitation retrieval.

\section{3) MRMS}

The MRMS system provides high spatiotemporal $\left(0.01^{\circ}\right.$ and $2 \mathrm{~min}$ ) quantitative precipitation estimate (QPE) and severe weather products over CONUS and southern Canada (Zhang et al. 2016). MRMS is underpinned by ground-based measurements from 146 U.S. S-band dual-polarization Weather Surveillance Radar-1988 Doppler (WSR-88D) instruments and 30 Canadian C-band single-polarization Environment Canada radars. These radar measurements are combined with data from 7000 rain gauges for QPE bias correction (except for snowfall), with inputs from hourly model analyses to aid in quality control of the radar measurements and precipitationtype identification (rain, snow, and hail). The gauge measurements are also subject to quality control. QPEs are typically produced by extrapolating the lowest elevation radar reflectivity factor measurement to the ground, determining the surface precipitation type, and then applying the reflectivityto-precipitation conversion for the respective precipitation type. This study uses the hourly radar V11 product with local gauge bias correction (GaugeCorr_QPE_O1H).

\section{b. CMIP6's NCAR and CNRM models}

CMIP6 models with hourly resolution are chosen for this analysis including: the Second Generation Earth System Model
(CNRM-ESM2.1), the coupled Climate Model (CNRM-CM6.1) and its high-resolution counterpart (CNRM-CM6.1-HR) from CNRM-CERFACS, and NCAR's version-2 Community Earth System Model (NCAR-CESM2). Atmospheric Model Intercomparison Project (AMIP) and Historical simulations are analyzed; AMIP is an atmosphere-only simulation from 1979 with the ocean constrained by observed sea surface temperatures (SST) and sea ice concentrations (SIC; Eyring et al. 2016), and Historical is a coupled atmosphere-ocean simulation starting from 1850 (preindustrial). Because of their prescribed SST and SIC observations, AMIP simulations can approximately capture large-scale circulation system positions (which follow SST patterns) and represent El Niño and La Niña event timings, unlike Historical simulations. Both simulation types include observed historical forcings and prescribed $\mathrm{CO}_{2}$ concentrations. Only NCAR and CNRM models are selected for this analysis, because they were the only models that performed hourly AMIP simulations at the time of analysis; available coupled and high-resolution hourly simulations from these models are also assessed. The CMIP6 models each include different physical components (WCRP 2020b) and have different spatial resolutions.

Representation of the diurnal cycle of precipitation is determined by each model's convective parameterization scheme (Table 1). NCAR-CESM2's atmospheric model parameterizes deep convection with a plume ensemble approach, where a conditionally unstable lower troposphere results in an ensemble of updrafts and downdrafts; moist convection occurs in the presence of convective available potential energy (CAPE; UCAR 2020). CNRM-CM6.1 parameterizes dry, shallow, and deep convection using a bulk mass flux scheme, with closure dependent upon a dilute CAPE relaxation (Voldoire et al. 2019; WCRP 2020a). CNRMESM2.1 employs the same convective parameterization scheme as CNRM-CM6.1, and only differs by including atmospheric chemistry, aerosols, and the carbon cycle (Séférian et al. 2019).

\section{c. ERA5 reanalysis}

The ERA5 global reanalysis (Hersbach et al. 2020) combines observations and models via 4D-Var data assimilation to provide a consistent record of the atmosphere, land, and ocean surfaces from 1979. Observations are assimilated in 12-h windows (0900-2100 UTC, and 2100-0900 UTC) within ECMWF's Integrated Forecasting System (IFS) Cy41r2, with the atmosphere coupled to land and ocean. A land data assimilation system is weakly coupled with this incremental 4DVar; daily sea surface temperature and sea ice concentration observations are also included. The IFS parameterizes deep, shallow, and midlevel convection using a bulk mass flux scheme, in which a pair of entraining and detraining plumes represent clouds within the grid box (ECMWF 2020). ERA5 assimilates 6-hourly precipitation estimates over CONUS from the National Centers for Environmental Prediction Stage IV radar-gauge product since 2009 (Lopez 2011; Hersbach et al. 2020). Brightness temperatures from GPM/TRMM PMW constellation members are also assimilated due to their sensitivity to precipitation and atmospheric humidity, though precipitation retrievals from these members are not assimilated.

ERA5 has finer spatiotemporal resolution $(31 \mathrm{~km}$ and hourly) than its predecessor, ERA-Interim, for capturing 
weather systems, and improved representation of global precipitation compared to GPCP. Furthermore, the diurnal cycle of convection is improved due to changes to the closure of CAPE (Bechtold et al. 2014), such that land-based precipitation now maximizes in the late afternoon rather than midday (Hersbach et al. 2020). This analysis uses the surface mean total precipitation rate ( $m t p r$ ) from ERA5, which includes rain and snow generated from the IFS cloud (coarser-than-pixel scale) and convection (subpixel scale) schemes (Hersbach et al. 2018).

\section{Method}

June-August (JJA) hourly precipitation data are analyzed, as diurnal variations are stronger over Northern Hemisphere land in boreal summer. Coincident JJAs across the range of selected CMIP6 simulations (1979-2008) are evaluated against the full IMERG JJA record (2000-19), and ERA5 is subsampled to the IMERG period. The respective multidecade periods are used to maximize signal to noise and provide relatively consistent results with the coincident 2000-08 period across all products (Fig. S1 in the online supplemental material). The DPR and MRMS products are only available from 2014 and 2015 , respectively. Only data from $60^{\circ} \mathrm{N}$ to $60^{\circ} \mathrm{S}$ are used for consistency, because IMERG coverage between $60^{\circ}$ and $90^{\circ} \mathrm{N} / \mathrm{S}$ is incomplete over snowy/icy surfaces where PMW estimates are unreliable (Huffman et al. 2019b). DPR data are gridded to $1^{\circ} \times 1^{\circ}$.

For each product, the mean precipitation accumulation $P$ at a given latitude $\phi$ and longitude $\lambda$ for each UTC hour $t_{\mathrm{UTC}}$ is determined by

$$
P\left(\phi, \lambda, t_{\mathrm{UTC}}\right)=\frac{\sum_{i=1}^{N} P_{i}}{N},
$$

where $P_{i}$ is the $i$ th precipitation estimate $\left(P_{i} \geq 0\right)$ within the respective study period and $N$ is the total number of precipitation estimates (including no precipitation). IMERG estimates are coarsened to hourly resolution prior to use in Eq. (1), and mean accumulations are then regridded to the spatial resolution of each selected CMIP6 and ERA5 product; this is done by oversampling the IMERG accumulations at $0.01^{\circ} \times$ $0.01^{\circ}$ - with each finer grid pixel retaining the accumulation of the coarser pixel-and then averaging all $0.01^{\circ}$ IMERG estimates whose grid pixel centers fall within a coarser CMIP6/ ERA5 grid pixel. The same procedure is applied to all products for the CONUS case study regions, which are coarser than each product's spatial resolution; this includes the DPR and MRMS products, which are only used in the CONUS analysis.

Parameters are then determined from the diurnal cycle of precipitation: diurnal precipitation mean, amplitude, and time of maximum. UTC hours are converted to local solar time $\left(\mathrm{LST} ; t_{\mathrm{LST}}\right)$ via

$$
t_{\mathrm{LST}}(\mathrm{h})=t_{\mathrm{UTC}}(\mathrm{h})+\frac{\lambda\left(^{\circ}\right)}{15\left({ }^{\circ} \mathrm{h}^{-1}\right)} .
$$

for the determination of the local time of maximum. Although many previous studies have fit harmonic functions or empirical orthogonal functions to diurnal cycles (Wallace 1975; Janowiak et al. 1994; Dai 2001, 2006; Dai and Trenberth 2004; Dai et al. 2007; Yang and Slingo 2001; Nesbitt and Zipser 2003; Kikuchi and Wang 2008; Covey et al. 2016; Watters and Battaglia 2019; Battaglia et al. 2020a; Minobe et al. 2020), this study does not use such a method to extract diurnal precipitation parameters (similar to, e.g., Dai et al. 1999; Kidd et al. 2013) because firstand second-order harmonics are sometimes insufficient in effectively capturing the diurnal variability (Dai et al. 1999). The only exception is that the DPR diurnal cycle is fit with 24- and 12-h harmonics [Watters and Battaglia 2019, their Eq. (4)], because of its limited sampling, which provides a low signal-tonoise ratio. The diurnal amplitude is determined as the half range of hourly accumulations, with the normalized amplitude defined as the ratio of the amplitude to the diurnal mean. The time of maximum is the LST of the maximum hourly accumulation.

The interannual variability (IAV) of the diurnal parameters from IMERG, NCAR, CNRM, and ERA5 is assessed and defined as the ratio of the standard deviation of the yearly parameters to the mean of the yearly parameters for diurnal precipitation mean and normalized amplitude - the standard deviation of the yearly parameters for the time of maximum. The cyclical nature of daily time (0000 LST = "2400" LST, i.e., 0000 LST of the next day) is accounted for when determining the IAV of the time of maximum. This is done by converting the time for each year to angles on a unit circle, computing the mean of each angle's Cartesian coordinates before converting back to a mean time (Jammalamadaka and SenGupta 1999); the standard deviation relative to this mean time is calculated using the minimum time difference between each yearly time and the mean time.

\section{CONUS evaluation of the observed and the simulated diurnal cycle of precipitation}

Evaluation of the diurnal cycle over CONUS and the Gulf Stream provides novel understanding of the differences between IMERG, NCAR, CNRM, and ERA5. Assessing the diurnal cycle where NCAR, CNRM, and ERA5 coincidentally simulate convection (i.e., mean vertical updrafts at $500 \mathrm{hPa}$ ) allows discrepancies with IMERG to be pinpointed to issues in the model's convection scheme (rather than mismatches in precipitation location); the Rocky Mountains and the Gulf Stream are two regions where ERA5, NCAR, and CNRM all simulate convection (Fig. 1a, regions 1 and 5). Furthermore, MRMS's gauge-adjusted ground-based radar observations provide a regional reference over CONUS. The MRMS regional reference supersedes the IMERG global reference in this analysis as radars directly sense the vertical structure of precipitation (Battaglia et al. 2020b), observing it close to the ground unlike IMERG's PMW and IR measurements (Watters and Battaglia 2020a); however, MRMS is restricted to CONUS coverage only, while IMERG provides global coverage with regular updates. Over CONUS, MRMS is used to further validate the diurnal cycle from IMERG, beyond previous studies (Sungmin and Kirstetter 2018; Tan et al. 2019a) by using more years of boreal summer estimates (IMERG: 20 years; MRMS: 6 years). This analysis also assesses the ability of 
a)

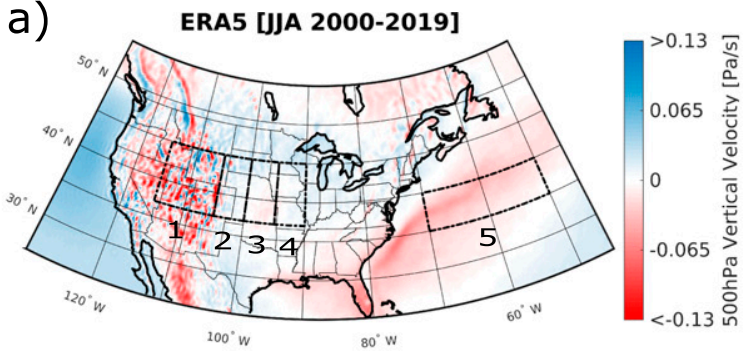

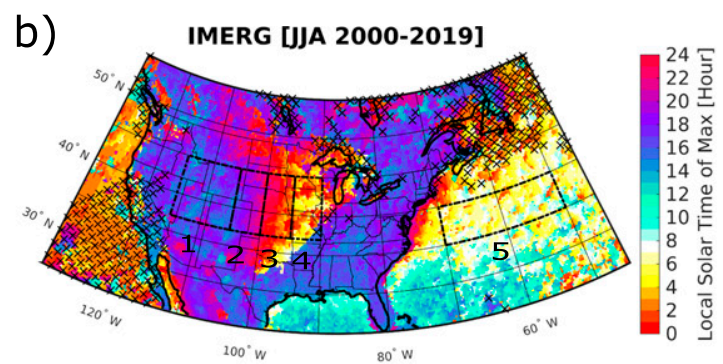

c)

1

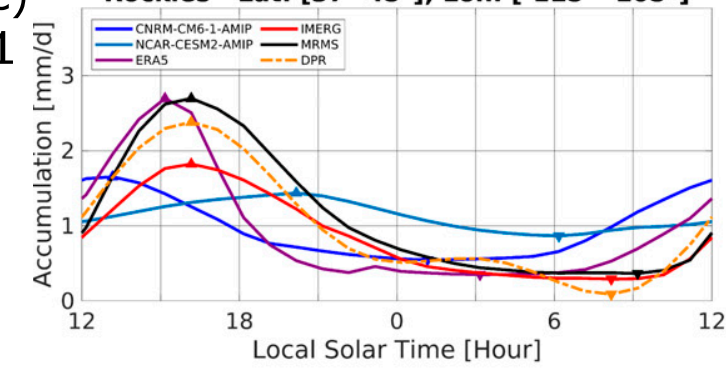

e) East Great Plains - Lat: $\left[37^{\circ} 45^{\circ}\right]$; Lon: [-100 $\left.-95^{\circ}\right]$

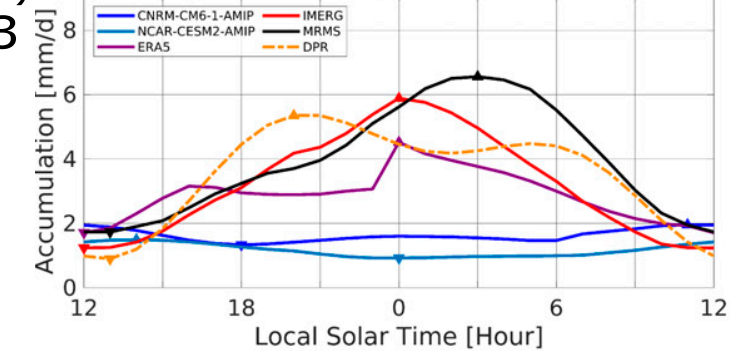

g)

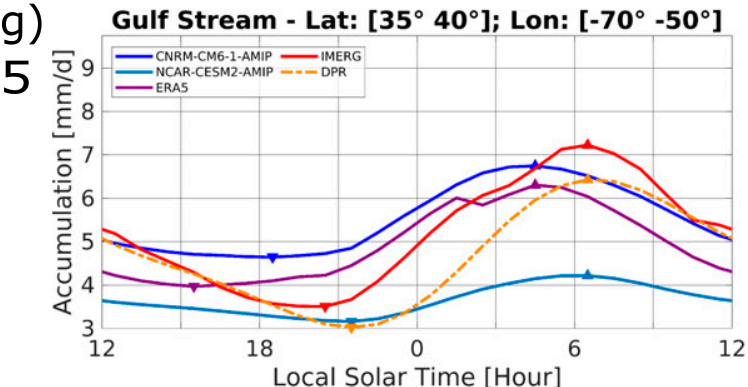

d)

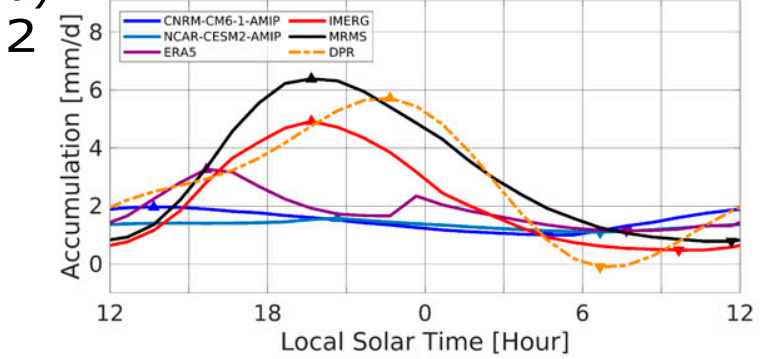

f)

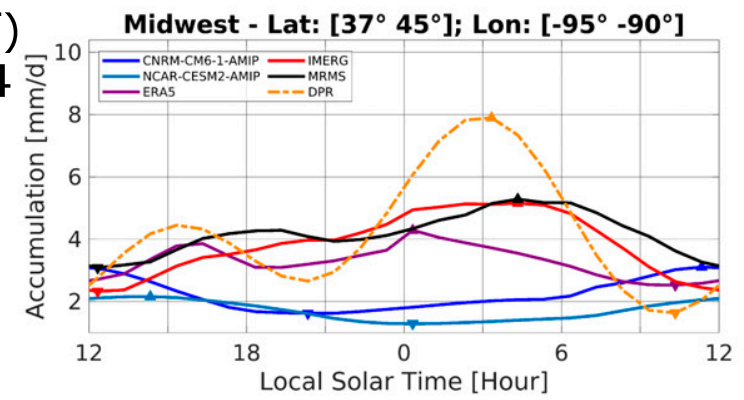

Solid - Original Cycle Dashed - Harmonic Fit Cycle

FIG. 1. The diurnal cycle of precipitation for boreal summer over CONUS and the Gulf Stream: CONUS map plots of (a) average vertical velocity at $500 \mathrm{hPa}$ from ERA5 (negative values represent updrafts) and (b) local solar time of maximum precipitation amount from IMERG, as in Fig. 6a, below. Hatched regions in (b) experience little precipitation (daily precipitation mean is less than $0.275 \mathrm{~mm}$; Fig. 2a, below) or have weak diurnal variations (normalized amplitude is less than 30\%; Fig. 4a, below), and hence their times of maximum precipitation amount are considered to be unreliable. (c)-(g) Diurnal cycle functions from IMERG, ERA5, NCAR, CNRM, MRMS, and DPR for each of the numbered regions in (a) and (b); a solid line represents an original cycle, and a dashed line depicts a diurnal cycle fit with a harmonic (24 and $12 \mathrm{~h}$ ) function. Upward-pointing symbols represent the maximum, and vice versa. Product periods are provided in Table 1. Regions 1-5 are referred to as the Rockies, west Great Plains, east Great Plains, Midwest, and Gulf Stream, respectively, in the text.

the spaceborne GPM-CO's radar (DPR) to capture the diurnal cycle of precipitation over CONUS for the first time; the DPR is limited to only seven boreal summers of low-Earth-orbit sampling at present, preventing its use in assessing NCAR, CNRM, and ERA5 at fine scales globally.
Figure 1 depicts five different regions where the diurnal cycle from IMERG, NCAR-CESM2 AMIP, CNRM-CM6.1 AMIP, ERA5, and DPR is assessed against MRMS; regions with spatial homogeneity in vertical wind velocities (from ERA5) and diurnal phase (from IMERG) are selected. 
a)

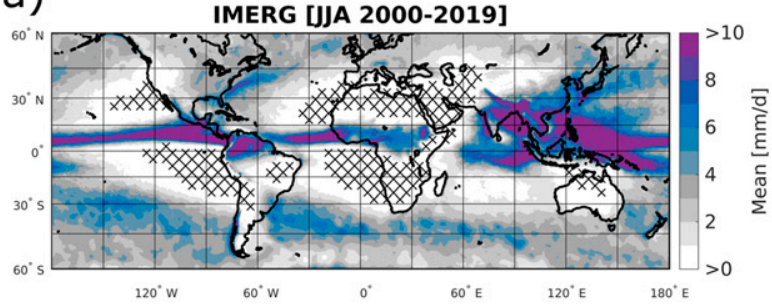

c)

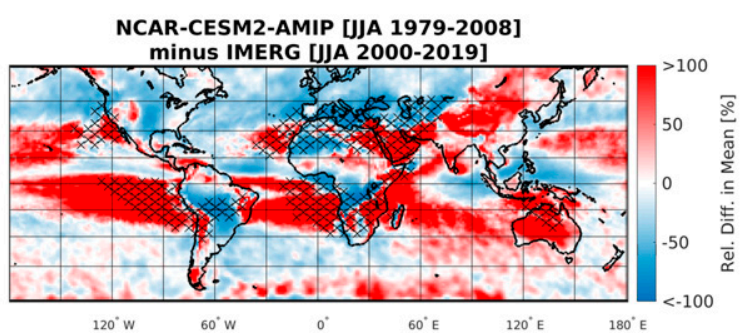

b)

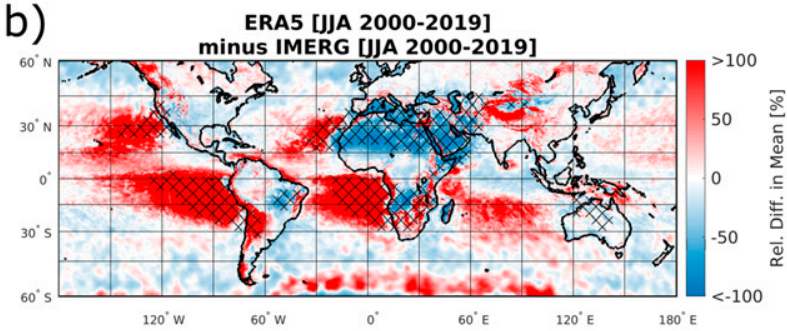

d)

CNRM-CM6-1-AMIP [JJA 1979-2008]

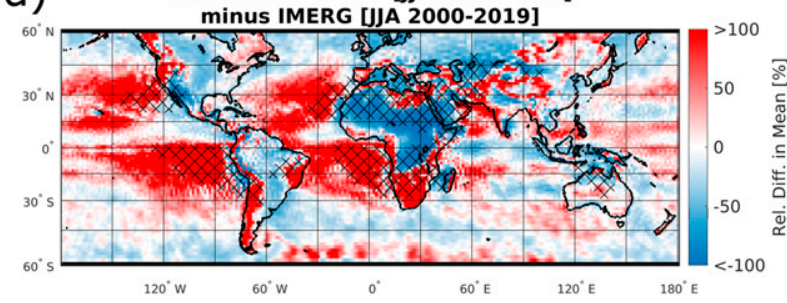

FIG. 2. Global maps of the precipitation mean from (a) IMERG, (b) ERA5 minus IMERG, (c) NCAR-CESM2 AMIP minus IMERG, and (d) CNRM-CM6.1 AMIP minus IMERG for their respective JJA multidecade study periods. The percentage difference uses IMERG as the denominator. Hatching covers those regions where the daily precipitation mean is less than $0.275 \mathrm{~mm}$ for either of the respective products within a panel.

While the Great Plains and Midwest (regions 2-4) show no predominance of updrafts or downdrafts on average, MCSs that form over the Rockies travel eastward over these regions. The nocturnal eastward propagation in diurnal phase depicted by IMERG due to these MCSs is consistent with previous observational studies (e.g., Wallace 1975; Dai et al. 1999; Trenberth et al. 2003; Dai et al. 2007; Dirmeyer et al. 2012; Sungmin and Kirstetter 2018; Tan et al. 2019a; Scaff et al. 2020). Bar charts comparing diurnal parameters between products for each region are provided in Fig. S2 in the online supplemental material. Note that the diurnal cycles of precipitation for NCAR-CESM2 AMIP and CNRM-CM6.1 AMIP are broadly consistent with their respective model's Historical simulations (i.e., diurnal parameter quantities can vary), while the diurnal cycles for CNRM-CM6.1 AMIP and CNRMESM2.1 AMIP closely match.

Regional comparisons of the diurnal cycle highlight that NCAR-CESM2 AMIP, CNRM-CM6.1 AMIP, and ERA5 are more consistent with observations over convection-susceptible regions. However, NCAR-CESM2 AMIP and CNRM-CM6.1 AMIP still exhibit large discrepancies in these regions; over the Rockies, the late afternoon maximum observed by MRMS, IMERG, and DPR (1600 LST) is simulated $4 \mathrm{~h}$ later by NCARCESM2 AMIP (2000 LST) and $3 \mathrm{~h}$ earlier by CNRM-CM6.1 AMIP (1300 LST). Over the Gulf Stream, which lacks MRMS coverage, NCAR simulates distinctively lower precipitation mean and normalized amplitude (NCAR-CESM2 AMIP: $3.7 \mathrm{~mm} \mathrm{day}^{-1}$ and 14\%; IMERG: $5.2 \mathrm{~mm} \mathrm{day}^{-1}$ and $36 \%$, respectively) than the other products. The selected CMIP6 atmosphere-only products tend to compare worst to MRMS over each CONUS region, as highlighted by simulating the smallest means (except over the Rockies) and the smallest normalized amplitudes (except over the Midwest).

IMERG tends to better compare to the CONUS reference, MRMS, than ERA5, NCAR-CESM2 AMIP, and CNRM-
CM6.1 AMIP. In particular, IMERG mostly captures the eastward propagation in the time of maximum (MRMS: 1600, 1900, 0300, and 0400 LST for regions 1-4); the exception is that IMERG observes a maximum in precipitation $3 \mathrm{~h}$ earlier than MRMS over the east Great Plains, which Sungmin and Kirstetter (2018) suggested may be caused by bias in IMERG's PMW observations toward the leading convective component of MCSs in this region. In comparison, ERA5 produces an eastward phase jump that is faster than observed, and NCARCESM2 AMIP and CNRM-CM6.1 AMIP simulate a false westward phase jump (ERA5: 1500, 1500, 0000, and 0000 LST; NCAR-CESM2 AMIP: 2000, 2000, 1400, and 1400 LST; CNRM-CM6.1 AMIP: 1300, 1300, 1100, and 1100 LST). Like MRMS, normalized amplitude also reduces eastward for IMERG (MRMS: $103 \%, 89 \%, 61 \%$, and $26 \%$ for regions $1-4$; IMERG: $90 \%, 102 \%, 71 \%$, and $36 \%$ ), except for the initial transition from the Rockies; alternatively, ERA5 captures MRMS's trend (ERA5: 124\%, 57\%, 48\%, and 27\%), although it typically differs more from MRMS than IMERG (except over the Midwest). While mainly comparing well to MRMS, IMERG can perform worse than ERA5, NCAR-CESM2 AMIP, and CNRM-CM6.1 AMIP in a few instances. IMERG, ERA5, and CNRM-CM6.1 AMIP all observe/simulate increases in the precipitation mean eastward like MRMS (MRMS: 1.1, 3.1, 4.0, and $4.2 \mathrm{~mm}$ day $^{-1}$; IMERG: 0.9, 2.2, 3.3, and $3.9 \mathrm{~mm}^{\text {day }}{ }^{-1}$ for regions 1-4), while IMERG performs worst over the Rockies (MRMS and NCAR-CESM2 AMIP: $1.13 \mathrm{~mm}^{-1}$ day $^{-1}$, DPR: $0.99 \mathrm{~mm} \mathrm{day}^{-1}$, CNRM-CM6.1 AMIP: $0.95 \mathrm{~mm}$ day $^{-1}$, ERA5: $0.94 \mathrm{~mm}$ day $^{-1}$, and IMERG: $0.85 \mathrm{~mm}_{\text {day }}{ }^{-1}$ ). This underestimation of Rockies precipitation reaffirms IMERG's tendency to underestimate precipitation in mountainous regions (Tapiador et al. 2020), and evaluation of ERA5, NCARCESM2 AMIP, and CNRM-CM6.1 AMIP, by precipitation mean in such regions should be treated with caution (Fig. 2). 
Another instance of IMERG biases affecting model comparisons is over the Midwest; IMERG overestimates the normalized amplitude, failing to capture it unlike ERA5 and NCAR-CESM2 AMIP (MRMS and NCAR-CESM2 AMIP: 26\%; ERA5: 27\%; CNRM-CM6.1 AMIP: 34\%; IMERG: $36 \%$ ). Overall, these findings reaffirm the skill of IMERG in representing the CONUS diurnal cycle of precipitation as proven by ground-based observations (albeit with some localized biases; Sungmin and Kirstetter 2018; Tan et al. 2019a), and that the use of IMERG is suitable for evaluating models.

At present, the DPR exhibits some skill in representing the diurnal cycle over CONUS when subject to harmonic fitting; the harmonic function fit to each region's original diurnal cycle is depicted in Fig. S3 in the online supplemental material. The DPR compares best to MRMS for precipitation mean across the Great Plains and Midwest and is only second to NCARCESM2 AMIP over the Rockies (with an underestimate of $0.14 \mathrm{~mm} \mathrm{day}^{-1}$ ). The DPR is erratic in representing the normalized amplitude: it compares best to MRMS over the Rockies (MRMS: 103\%; DPR: 115\%) and the east Great Plains (MRMS: 61\%; DPR: 62\%), but significantly overestimates in the Midwest (MRMS: 26\%; DPR: 74\%). Even while capturing the amplitude in the east Great Plains, the DPR's diurnal function is anomalous with a broad peak that spans $\sim 10 \mathrm{~h}$. DPR performance for the time of maximum is erratic too, though typically better than ERA5, NCAR-CESM2 AMIP and CNRM-CM6.1 AMIP (except for the east Great Plains): DPR aligns with MRMS and IMERG over the Rockies, is one hour earlier over the Midwest, and differs by $>$ 3 h over the Great Plains.

\section{Global evaluation of the simulated diurnal cycle of precipitation}

Diurnal precipitation parameters from NCAR, CNRM, and ERA5 are evaluated against reference IMERG across the globe. From CMIP6, only map plots for CNRM-CM6.1 AMIP and NCAR-CESM2 AMIP are presented because of the broad consistency in the diurnal cycle of precipitation between different simulations from CNRM (CNRM-CM6.1: AMIP, Historical, HR Historical; CNRM-ESM2.1: AMIP) and from NCAR (NCARCESM2: AMIP, Historical), respectively (Figs. 3a and 5a and also Fig. S4 in the online supplemental material); consequently, CNRM-CM6.1 AMIP and NCAR-CESM2 AMIP are respectively referred to as CNRM and NCAR when discussing the global results. IMERG results are presented at $0.25^{\circ} \times 0.25^{\circ}$ (ERA5's spatial resolution); the only exception is that IMERG is regridded to the respective CMIP6 product's spatial resolution for CMIP6 minus IMERG results.

\section{a. Precipitation mean}

Figure 2 depicts the comparison of the precipitation mean across the globe. Hatched regions experience little precipitation $\left(<0.275 \mathrm{~mm} \mathrm{day}^{-1}\right)$, and hence their diurnal variations are considered unreliable and their diurnal parameters are excluded from statistics (unless stated). IMERG observes high precipitation amounts across the tropics, especially between $0^{\circ}$ and $15^{\circ} \mathrm{N}$ where the intertropical convergence zone (ITCZ) a)

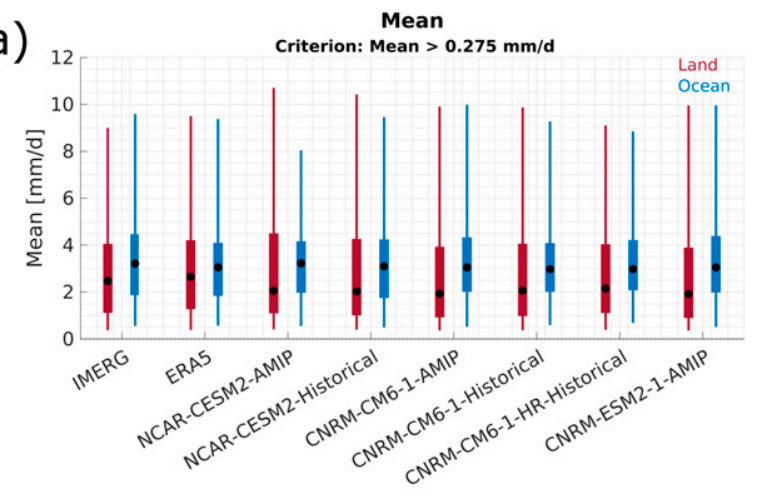

b)

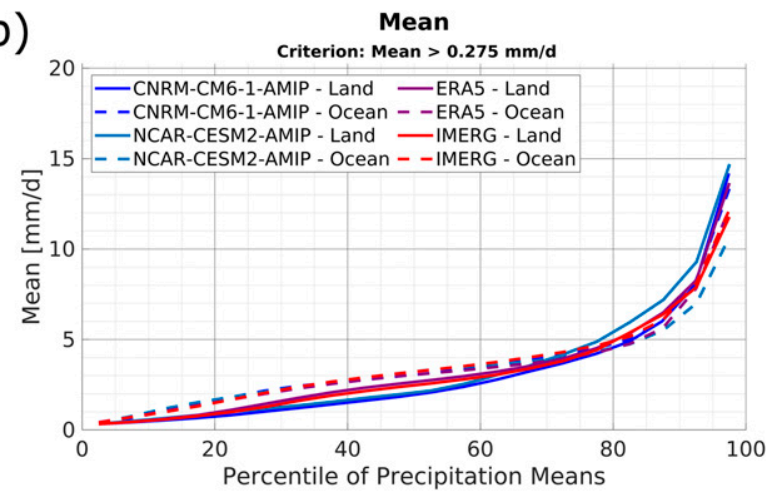

c)

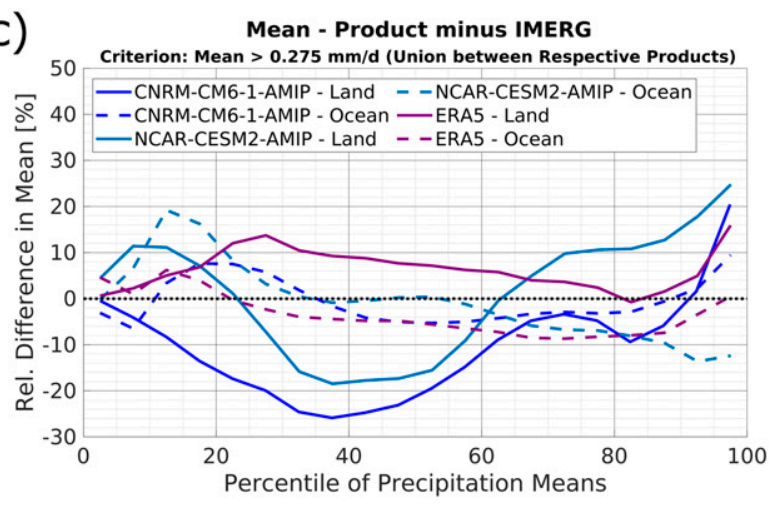

FIG. 3. The global distribution of precipitation means from IMERG, NCAR, CNRM, and ERA5 for their respective JJA multidecade study period, represented (a) by boxplots and (b) as a function of the percentile of precipitation mean. For the respective product, only grid pixels with daily precipitation mean exceeding $0.275 \mathrm{~mm}$ are included. Whiskers on boxplots extend from the 5 th to the 95 th percentiles, boxes extend from the 25 th to the 75 th percentiles, and black circles indicate the 50th percentile for the respective surface (land is red; ocean is blue) and product; these percentiles do not account for varying pixel area by latitude. Percentile functions are deduced as the average precipitation mean from grid pixels with precipitation means within each 5 th percentile $(0-5$ th percentile, ..., 95th100th percentile). (c) The difference in percentile functions between NCAR, CNRM, or ERA5 and IMERG, normalized to the IMERG percentile function. 
a)

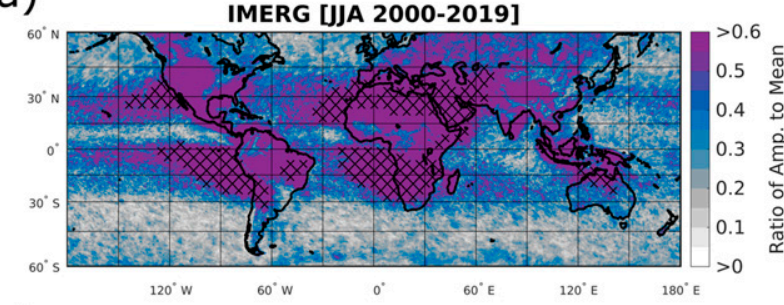

c)

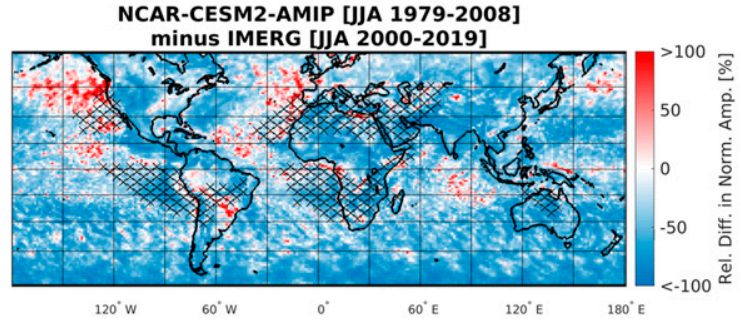

b)

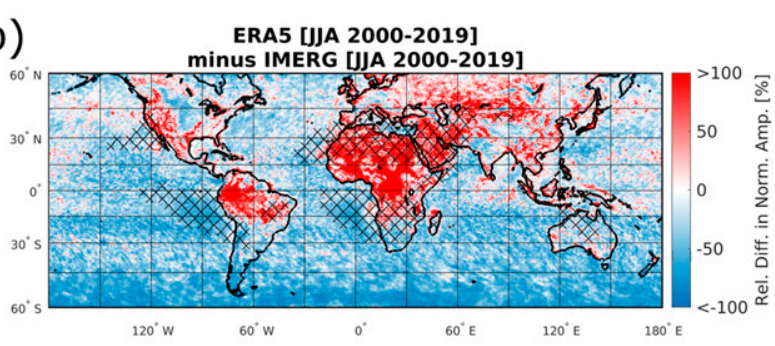

d)

CNRM-CM6-1-AMIP [JJA 1979-2008]

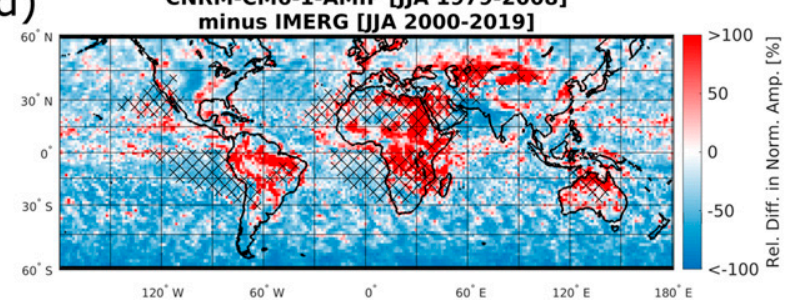

FIG. 4. As in Fig. 2, but for normalized amplitudes; hatching covers regions under the same low-precipitation criterion also.

resides in boreal summer. Dry regions are typically located either side of the ITCZ.

ERA5 better captures observed precipitation than NCAR and CNRM in many regions, especially over land where the models typically simulate less precipitation (with exceptions over Asia). ERA5, NCAR, and CNRM exceed observed precipitation around the Himalaya Mountains, the Andes, and the Rocky Mountains, though this may be due to IMERG underestimating precipitation in mountainous regions (Tapiador et al. 2020). Further exceedance of IMERG precipitation occurs in the drier regions of the tropical and subtropical oceans. Notably, CNRM produces much less precipitation over central Africa $\left(<1 \mathrm{~mm}\right.$ day $\left.^{-1}\right)$ than IMERG, NCAR, and ERA5 $\left(>5 \mathrm{~mm} \mathrm{day}{ }^{-1}\right)$. IMERG appears to produce anomalously low JJA precipitation over the South Atlantic and Indian Oceans $\left(45^{\circ}-60^{\circ} \mathrm{S}\right)$, which is not identified at the annual scale (Watters and Battaglia 2020b).

Map plots like Fig. 2 depict regional differences between NCAR/CNRM/ERA5 and IMERG, which can be affected by mismatches in observed and simulated locations/intensities of convection. Figure 3 compares the global distribution of precipitation means from each product using boxplots and percentile function plots (i.e., diurnal parameter average for each 5 th percentile of precipitation means, where the parameter is the precipitation mean in this instance), which removes the impact of regional mismatches. The global distribution plots depict the consistency in precipitation means, highlighting that regional discrepancies between NCAR/CNRM/ERA5 and IMERG compensate across global land and ocean. Global mean precipitation for JJA $\left(60^{\circ} \mathrm{N}-\mathrm{S}\right.$, inclusive of hatched regions and weighted by pixel area) is also consistent between products $\left(\sim 3.2 \mathrm{~mm} \mathrm{day}^{-1}\right)$ and falls within the energy budget constraints on annual global mean precipitation (2.7-3.4 $\mathrm{mm} \mathrm{day}^{-1}$ )/latent heat flux (78-98 $\mathrm{W} \mathrm{m}^{-2}$; Stephens et al. 2012). Differences in precipitation means are small across all precipitation regimes (between $-25 \%$ and $+25 \%$ of IMERG precipitation for each 5 th percentile; Figs. 3b and 3c). Further comparisons of precipitation means are left to future studies, with this study focusing on the diurnal cycle.

\section{b. Diurnal normalized amplitude}

Figure 4 depicts the global comparison of diurnal amplitudes (normalized by precipitation means in Fig. 2). IMERG observes that normalized amplitudes are typically larger over land $(26 \%-54 \%-134 \%$; 5 th-50th-95th percentile) than over ocean (14\%-28\%-66\%; Figs. $4 a$ and 5a). These amplitude ranges are similar to the 24 -h harmonic mean-to-peak amplitude ranges of $30 \%-100 \%$ over land and $10 \%-30 \%$ over ocean identified by Dai et al. (2007) and Covey et al. (2016) from a gamut of observation products (including TRMM TMPA); this study's upper extents likely exceed those from the preceding studies since the fitting of harmonics to the diurnal cycle can dampen amplitudes (Tan et al. 2019a). IMERG also identifies a clear difference in oceanic diurnal amplitudes outside of $30^{\circ} \mathrm{S}-$ $45^{\circ} \mathrm{N}$, with amplitudes rising from $13 \%-21 \%-34 \%$ within $60^{\circ}-$ $30^{\circ} \mathrm{S}$ to $19 \%-36 \%-71 \%$ within $30^{\circ}-0^{\circ} \mathrm{S}$; this suggests that oceanic diurnal variations in precipitation are related to insolation.

ERA5, NCAR, and CNRM typically display smaller diurnal amplitudes over ocean than IMERG (Figs. 4b-d). Damped normalized amplitudes in the NCAR/CNRM AMIP and Historical simulations (Fig. 5a) are likely due to limited diurnal variability in their respective prescribed (monthly mean) and simulated SSTs (to which atmospheric convection is closely coupled; Dai and Trenberth 2004). Over land, NCAR also underestimates normalized amplitudes, while CNRM and ERA5 both typically overestimate across the tropics and central Asia. However, ERA5's amplitude overestimates are widespread across Northern Hemisphere and tropical land, unlike for CNRM, where insolation is greater in boreal summer; this suggests that ERA5's convection parameterization is too strong. ERA5 best compares to the median observed amplitude over land $(20 \%-62 \%-185 \%)$ and over ocean $(6 \%-$ $19 \%-50 \%)$, while NCAR performs worst over land $(8 \%-$ 

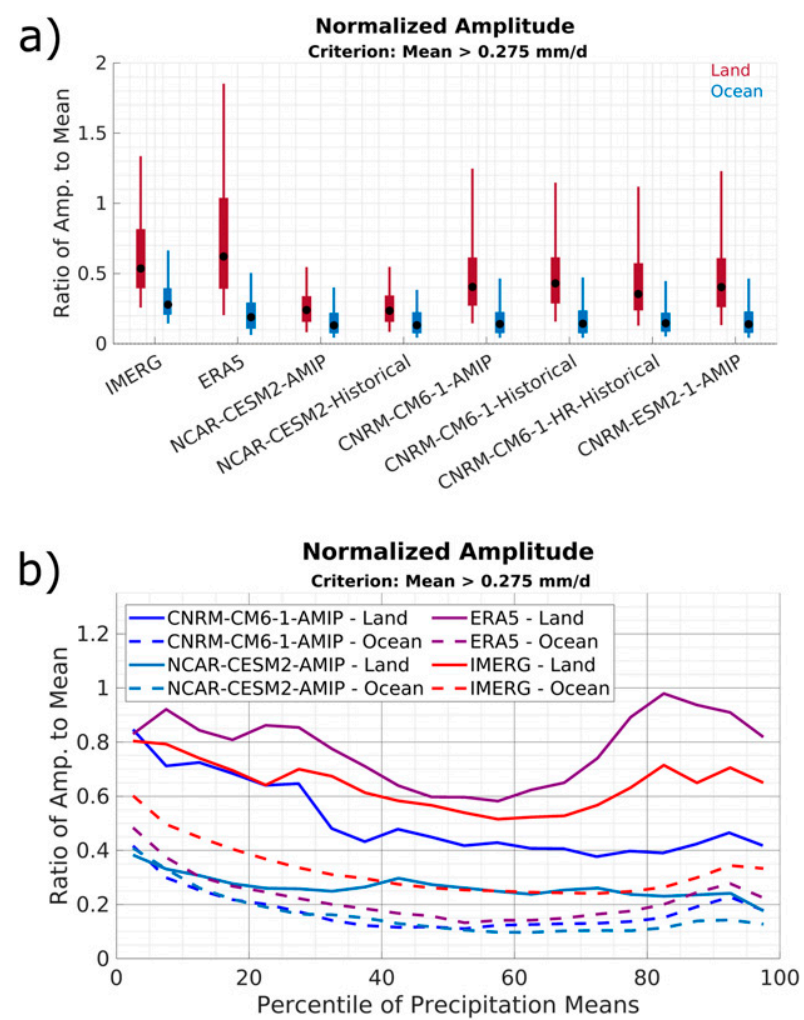

FIG. 5. As in Figs. 3a and 3b, but for normalized amplitude, using only those grid pixels for which daily precipitation mean exceeds $0.275 \mathrm{~mm}$ as previously. Note that (b) presents the average normalized amplitude from grid pixels with precipitation means within each 5th percentile (i.e., average normalized amplitude as a function of precipitation mean).

$24 \%-55 \%)$ and over ocean $(4 \%-13 \%-40 \%$; Fig. 5a). These findings are in contrast to the relative agreement in normalized amplitudes between CMIP5 models and TRMM TMPA identified by Covey et al. (2016), although this may be due to their use of harmonics on different models (at higher resolution) and a different observational product. Alternatively, the tendency for ERA5 to overestimate observed amplitudes over land and underestimate over ocean was also identified with the ECMWF operational forecast model (Kidd et al. 2013); underestimation in diurnal amplitudes over the ITCZ is a novel finding of this study.

Figure 5b highlights that normalized amplitudes decrease with increasing precipitation mean over land and ocean (except for NCAR over ocean), before increasing in the wettest regions ( $>60$ th percentile, except for NCAR and CNRM over land). NCAR and CNRM fail to fully capture these distinct trends in amplitude, with IMERG and ERA5 suggesting that diurnal normalized amplitudes are greater in the wettest regions on Earth than those with average precipitation. Also, CNRM shows some skill in capturing diurnal amplitudes in the driest land regions ( $<22$ nd percentile), while ERA5 exhibits skill in the average precipitation regions over land (40th-60th percentile).

Notably, normalized amplitudes for each product's multidecade period are smaller than for the product-coincident 2000 08 period by up to a factor of $1 / 4$ or $1 / 8$ on average over global ocean or land, respectively (Fig. S1b in the online supplemental material). This may be because the IAV of the time/position of the diurnal maximum may dampen the amplitude over a longer period of averaging. Analyzing multidecade amplitudes is considered to be appropriate since the diurnal cycle signal should be better captured over a longer period.

\section{c. Diurnal time of maximum}

Figure 6 depicts the global comparison of the local solar time of maximum. Hatched regions now cover those regions where the normalized amplitude is less than $30 \%$ for IMERG or $20 \%$ for NCAR, CNRM, and ERA5 (Fig. 4), as well as lowprecipitation regions $\left(<0.275 \mathrm{~mm}^{-1 a y}{ }^{-1}\right.$; Fig. 2$)$. The regions with amplitudes below the threshold tend to exhibit spatially inhomogeneous phase patterns, which are treated as anomalous due to weak diurnal variations; the thresholds are selected to ensure similar coverage across datasets and tend to cover southern midlatitude ocean regions.

IMERG observes precipitation over land to maximize from late afternoon to evening (1400-2100 LST), with late-evening to midmorning peaks (2100-0600 LST) close to mountainous regions (i.e., the Rockies, the Andes, and the Himalayas) and regions with varying terrain (central Africa and northeastern South America; Figs. 6a and 7a). Previous observational studies agree with late afternoon to evening peaks over land (e.g., Yang and Slingo 2001; Dai et al. 2007, etc.; see section 1), although IMERG's northern midlatitude peaks appear to occur a few hours after those from surface weather reports and to better align with convective precipitation peaks alike other satellite products (Dai 2001, 2006; Dai et al. 2007); potential IMERG biases could be due to the heightened sensitivity of PMW and IR measurements to deep convection (Dai et al. 2007), and could be exacerbated by the three-hourly resolution of the weather reports. The nocturnal mountainous peaks are only identified by observations with subdegree spatial resolution (Yang and Slingo 2001; Dai 2006; Covey et al. 2016; Minobe et al. 2020); this highlights the importance of high resolution global observations, as preceding IMERG analyses at $2^{\circ}$ and $5^{\circ}$ failed to capture these localized nocturnal phase propagations (Watters and Battaglia 2019; Battaglia et al. 2020a). NCAR, CNRM, and ERA5 simulate maximum precipitation over land earlier than IMERG (median pixel difference; NCAR: $-1 \mathrm{~h}$; ERA5: $-2 \mathrm{~h}$; CNRM: $-4 \mathrm{~h}$ ), reaffirming the tendency for convection-parameterized models to simulate precipitation too early with varying performance (e.g., Trenberth et al. 2003; Dirmeyer et al. 2012; Covey et al. 2016, etc.; see section 1). NCAR simulates diurnal peaks in precipitation from late morning to midevening (1000-2100 LST), with some late-evening to early-morning peaks over central Africa and the Eurasian Plateau (2200-0600 LST; Figs. 6c and 7a). CNRM peaks from midmorning to midafternoon (0800-1600 LST), with evening to early-morning peaks (1900-0200 LST) close to tropical coastlines and the Eurasian Plateau (Figs. 6d and 7a). ERA5 precipitation peaks from late morning to late afternoon (1100-1800 LST) and captures some observed nocturnal regional variations such as the eastward propagation of MCSs from the Rockies and the Andes, though simulates travel faster than observed (0000-0400 LST; Figs. 6b and 7a). 
a)

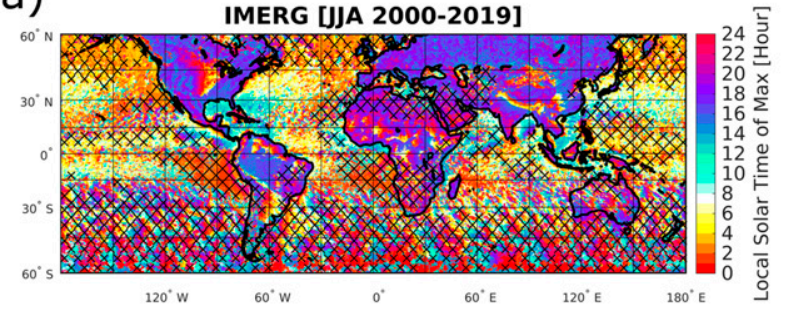

c)

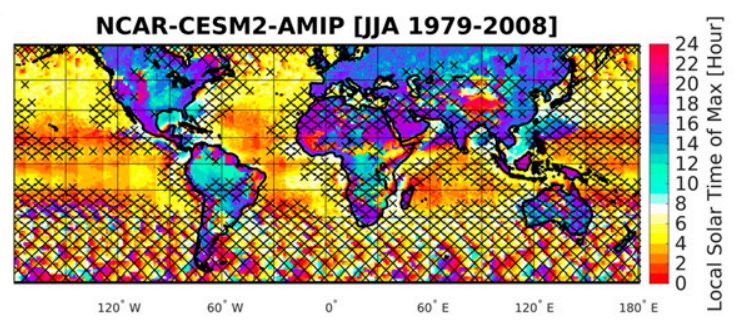

b)

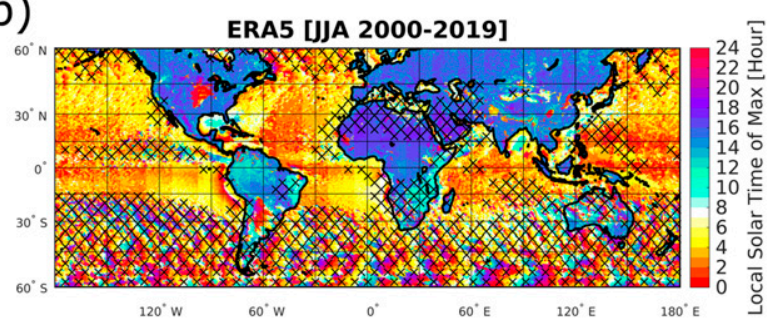

d)

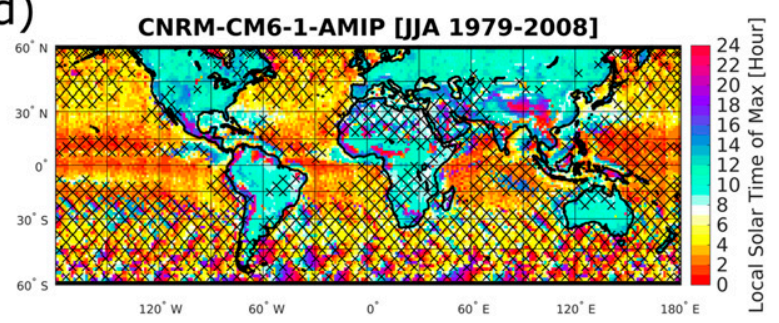

FIG. 6. Global maps of the local solar time of maximum from (a) IMERG, (b) ERA5, (c) NCAR-CESM2 AMIP, and (d) CNRM-CM6.1 AMIP for their respective JJA multidecade study period. Hatching covers those regions where the daily precipitation mean is less than $0.275 \mathrm{~mm}$ (Fig. 2) or the normalized amplitude is less than a certain threshold (30\% for IMERG and 20\% for NCAR, CNRM, and ERA5; Fig. 4) for the respective product.

ERA5 and CNRM better capture the observed spatial distribution of diurnal phase than NCAR over flatter terrain; ERA5 exhibits some skill at capturing variations in mountainous regions, potentially advantaged by its assimilation of observations, unlike NCAR and CNRM.

Over ocean, IMERG observes that precipitation maximizes from early morning to midday (0000-1200 LST), with tropical coastal waters maximizing from midmorning to midday (06001200 LST; Figs. 6a and 7b); this is in agreement with other studies (e.g., Yang and Slingo 2001; Dai et al. 2007, etc.; see section 1), though appears to lag surface weather reports by a few hours in open waters (Dai 2001, 2006; Dai et al. 2007). Also, some afternoon/evening phases occur in the Southern Hemisphere. NCAR, CNRM, and ERA5 better compare to the observed time of maximum over ocean than over land (median pixel differences; NCAR: $0 \mathrm{~h}$; ERA5 and CNRM: $-1 \mathrm{~h}$ ); however, they fail to capture the observed bimodal oceanic distribution (peaks at 0100 and 0600 LST). NCAR, CNRM, and ERA5 also estimate oceanic precipitation to maximize from early to late morning (0000-1100 LST), with CNRM better capturing observed coastal late morning maxima (Figs. 6b-d and 7b). Regional differences to IMERG are greater away from continents, with simulated areal coverage of late morning coastal phases smaller than observed (e.g., Gulf of Mexico and the "Maritime Continent"). Simulated spatial distributions are also more homogeneous compared to observations.

IMERG observes similar late afternoon and evening phases across all precipitation regimes over land, while precipitation maximizes later in the morning over wetter regions (Fig. 7c). NCAR, CNRM, and ERA5 do not capture the variation in the time of maximum with increasing precipitation over land or ocean. However, NCAR simulates the observed diurnal phase over the wettest land regions ( $>85$ th percentile); NCAR and ERA5 capture the time of maximum over the driest ocean regions
( $<20$ th percentile), with CNRM agreeing with IMERG over the wettest ocean regions ( $>90$ th percentile).

Future studies could further investigate IMERG's oceanic bimodal distribution in the time of maximum precipitation (Figs. 6a and 7b), which peaks between 0000 and 0300 LST (maximum at $0100 \mathrm{LST}$ ) and between 0400 and 0700 LST (maximum at 0600 LST) and appears to originate from different single-peak cycles in different regions: in the northern midlatitude oceans, 0000-0300 LST maxima typically occur in eastern waters, while 0400-0700 LST maxima occur in western and central waters.

\section{d. Interannual variability of the diurnal cycle}

IAV, a measure of the variability in the climate system, quantifies the deviation in the diurnal cycle throughout the respective product's multidecade period. Precipitation mean and diurnal phase are mostly consistent whether deduced from one multidecade-sampled diurnal cycle (multidecade parameter, as used in preceding results), or from the average parameter across $N$ different yearly sampled diurnal cycles (yearly average parameter, as used in the IAV calculation); this implies that the IAV in the respective parameter is representative of the deviation in the multidecade parameter. However, this is not the case for normalized amplitude, where the yearly averaged amplitude is several times greater than the multidecade amplitude (not shown). Because of the differing multidecade periods between IMERG-ERA5 and NCAR-CNRM in which different El Niño events can have differing effects on the IAV of precipitation, only ERA5 results are directly compared with IMERG in this section (although some NCAR and CNRM results are also shown).

Figure 8 depicts the global distribution of the IAV for each diurnal precipitation parameter; only those pixels that satisfy the multidecade criteria for each parameter are included. IAV 
a)

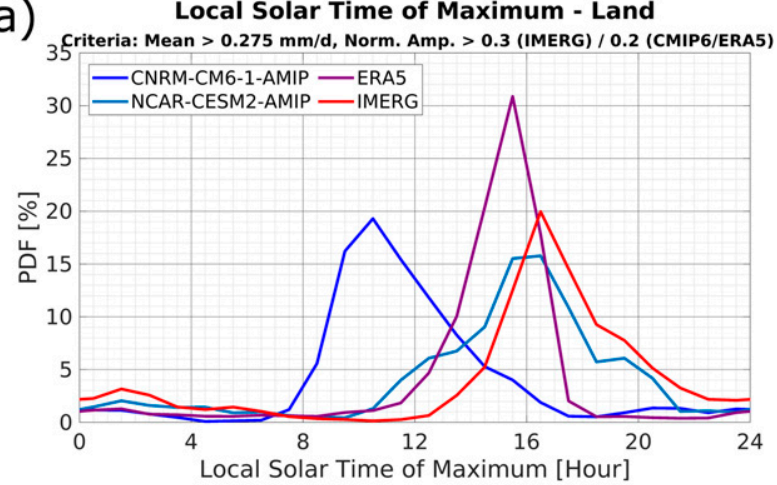

b) Local Solar Time of Maximum - Ocean

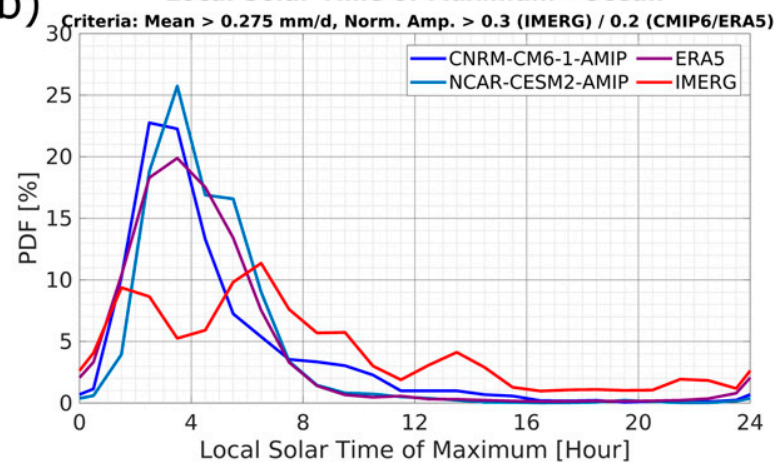

c)

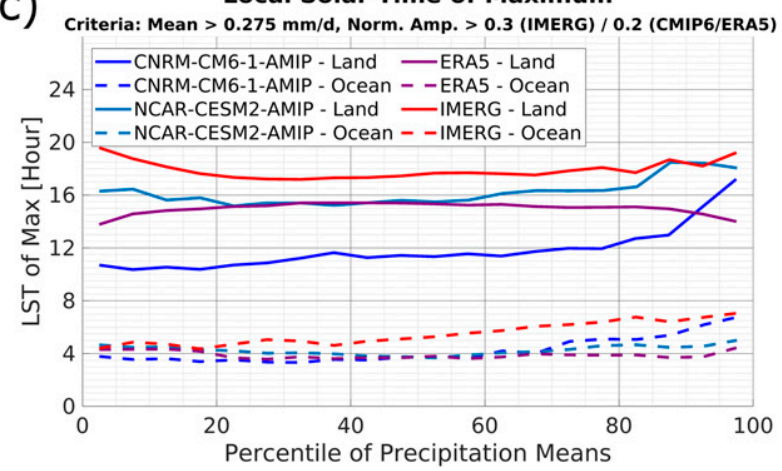

FIG. 7. The global distribution of the local solar time of maximum from IMERG, NCAR, CNRM, and ERA5 for their respective JJA multidecade period, represented by probability density functions (PDFs) for (a) land and (b) ocean and (c) as a function of the percentiles of precipitation mean. For the respective product, only grid pixels with daily precipitation mean exceeding $0.275 \mathrm{~mm}$ and with normalized amplitude $>30 \%$ for IMERG or $>20 \%$ for NCAR, CNRM, and ERA5 are used (i.e., the grid pixels without hatching in Fig. 6). Percentile functions are deduced as the average time of maximum from grid pixels with precipitation means within each 5 th percentile ( 0 th-5th percentile, ..., 95th-100th percentile). Figure S4 in the online supplemental material exhibits the PDFs for the remaining NCAR and CNRM simulations from Table 1.

distributions for precipitation means and normalized amplitudes are generally small on average (medians $<42 \%$ and $36 \%$, respectively, inclusive of NCAR and CNRM results), and relatively consistent between products and between land and
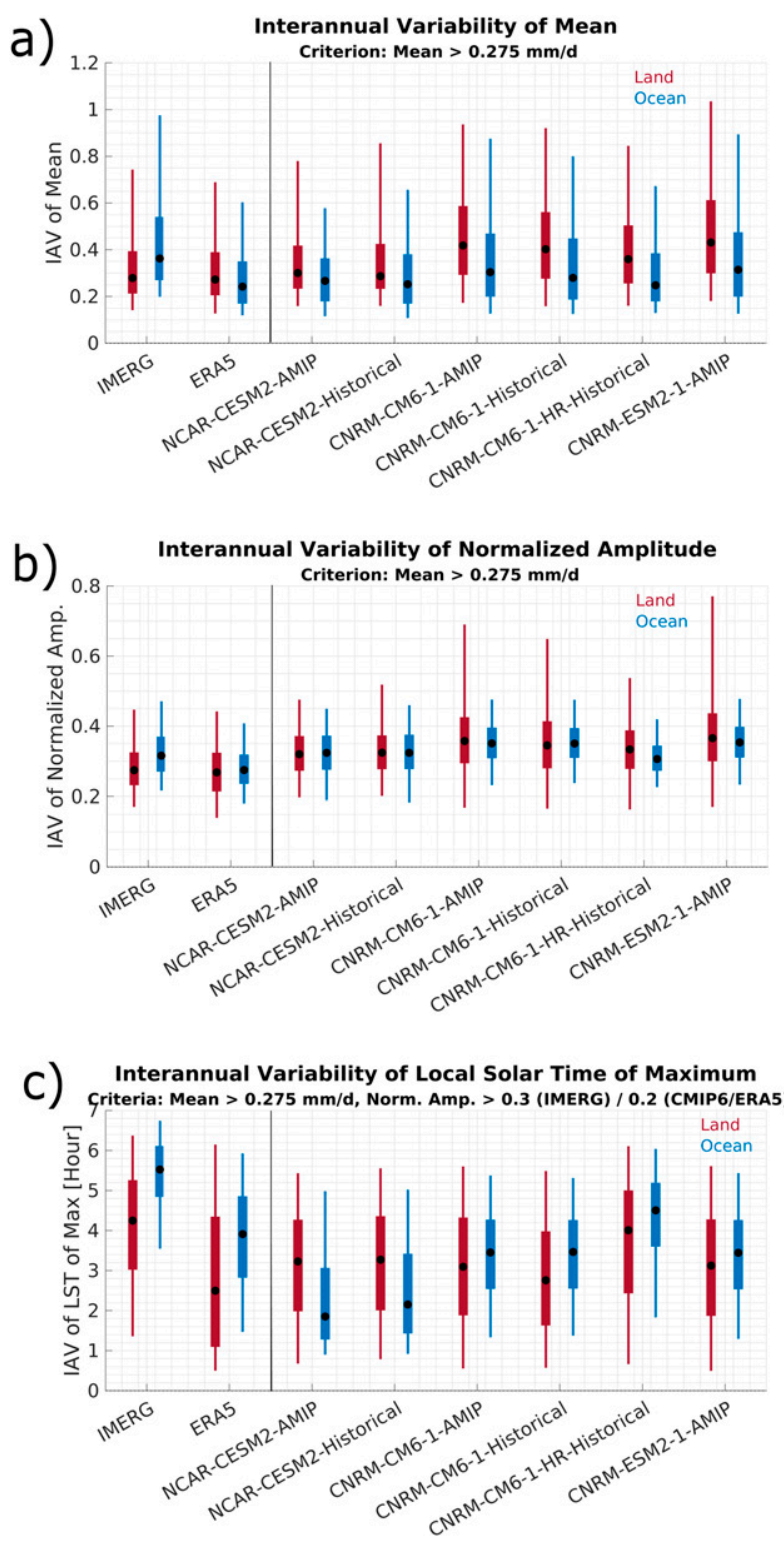

FIG. 8. The global distribution of IAV from IMERG, NCAR, CNRM, and ERA5 for their respective JJA multidecade periods, represented by boxplots for (a) precipitation mean, (b) normalized amplitude, and (c) local solar time of maximum. For the respective product, only grid pixels with daily precipitation mean exceeding $0.275 \mathrm{~mm}$ (and with normalized amplitude $>30 \%$ for IMERG or $>20 \%$ for NCAR, CNRM, and ERA5, when considering the IAV in the time of maximum) determined from the multidecade sample are used. Because of the differing multidecade JJA periods between IMERG-ERA5 (2000-19) and NCAR-CNRM (19792008), only ERA5's IAV results can be directly compared with those from IMERG.

ocean; while comparable to IMERG over land, ERA5's oceanic IAV is smaller. On the other hand, IAVs for the time of maximum are generally large, and more inconsistent between products and between land and ocean. IMERG observes IAVs in the time of maximum of $1.4-4.2-6.4 \mathrm{~h}$ (5th-50th-95th 
a)

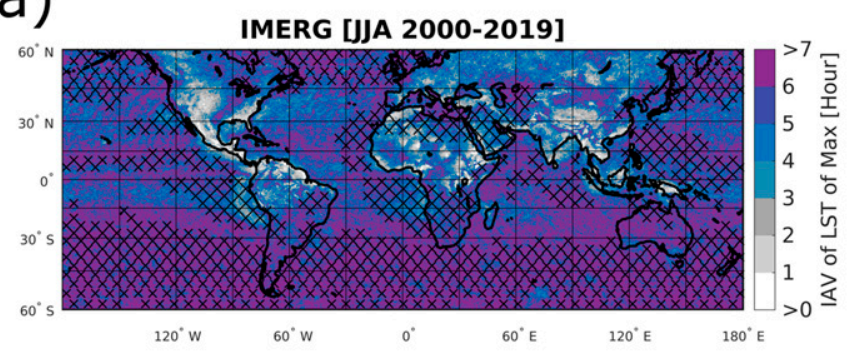

C)

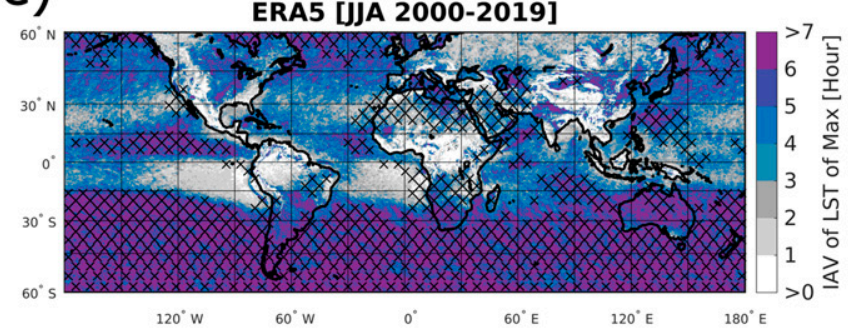

b) IMERG [JJA 2000-2019]

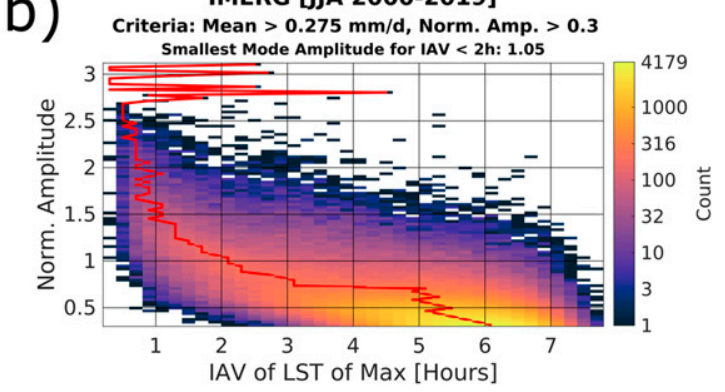

ERA5 [JJA 2000-2019]

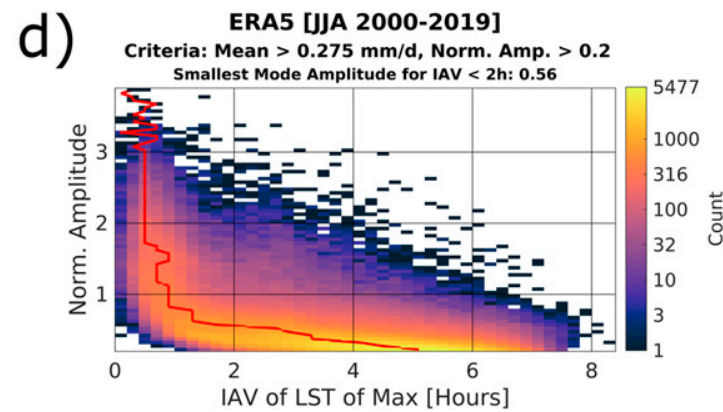

FIG. 9. Global map plots of the IAV in the local solar time of maximum from (a) IMERG and (c) ERA5 for JJA 2000-19. Also shown are density scatterplots for the normalized amplitude (determined from the whole 20-yr sample; Fig. 4) vs the IAV in the time of maximum from (b) IMERG and (d) ERA5. For the respective product, only grid pixels with daily precipitation mean exceeding $0.275 \mathrm{~mm}$ and with normalized amplitude $>30 \%$ for IMERG or $>20 \%$ for ERA5 determined from the multidecade sample are used; hatched regions do not satisfy these criteria. The red line in the density scatterplots represents the IAV bin with the highest count for each normalized amplitude bin.

percentiles) over land and 3.5-5.5-6.7 h over ocean; ERA5 exhibits smaller IAVs relative to IMERG.

The IAV in the diurnal phase has distinct regional features (Fig. 9). IMERG observes that the diurnal time of maximum accumulation is only consistent from year to year over Central America, the southeastern United States, the Rocky Mountains, southeastern Asia, and eastern central Africa (IAV $<2 \mathrm{~h})$. These regions also experience the greatest diurnal normalized amplitudes $(>105 \%)$; the density scatterplot highlights that as normalized amplitude increases, the IAV in the diurnal phase decreases. These findings echo those of Dai et al. (1999) for diurnal precipitation occurrence over CONUS. In contrast, ERA5 simulates relatively consistent diurnal phases from year to year across most tropical and Northern Hemisphere land, and tropical oceans west of the continents; furthermore, ERA5 simulates these low IAV regions typically where the normalized amplitude exceeds $56 \%$ (IAV $<2$ h; Fig. 9d). For both products, the IAV in the diurnal phase is correlated with the number of prominent peaks in the multidecade diurnal cycle (not shown). This suggests that ERA5's diurnal cycle representation is too simplified, simulating the diurnal phase to be more consistent from year to year than observed across many land regions and the adjacent oceans.

These results highlight the importance of satellite constellations in consistently tracking global precipitation, which exhibits strong climatological fluctuations in the time of maximum across the globe. Furthermore, this showcases the need for GPM PMW constellation members to be replaced when reaching the end of their lifespan; the GPM constellation is expected to dwindle from 12 different satellites in 2020 to 7 members by 2030 (Watters and Battaglia 2020b), reducing the revisit time of the constellation and its ability to track precipitation on short time scales. Future studies could investigate impacts on the IAV in IMERG's diurnal cycle caused by the evolution of GPM constellation sensors with time, IMERG's merging and interpolation of a multitude of satellite retrievals, and noise from a diurnal cycle averaged each year over the 92 days of JJA.

\section{Conclusions}

This study has evaluated the performance of CMIP6's NCAR and CNRM models and the ERA5 reanalysis against IMERG observations in representing the diurnal cycle of precipitation accumulation for boreal summer across the globe. To the knowledge of the authors, the study provides the first multidecade global diurnal cycle analysis with IMERG; the first multidecade global evaluation of the diurnal cycle of CMIP6's NCAR and CNRM models; the first global diurnal cycle evaluation of ERA5; and the first global investigation of the interannual variability of the precipitation diurnal cycle. Only CMIP6's NCAR and CNRM simulations and ERA5 reanalysis at hourly resolution were used, with IMERG matched to the spatiotemporal resolution of each product for comparison. Differing multidecade periods between IMERG-ERA5 and NCAR-CNRM were selected (Table 1), because of 
the relative consistency of the diurnal cycle between each respective multidecade period and the coincident 9 -yr period between the global-gridded products (Fig. S1 in the online supplemental material). Regions with low precipitation means $\left(<0.275 \mathrm{~mm} \mathrm{day}^{-1}\right)$ were excluded from all analyses, as were regions with weak normalized amplitudes $(<30 \%$ for IMERG and $<20 \%$ for NCAR, CNRM, and ERA5) when analyzing the time of maximum, to avoid biasing the comparison results.

An initial analysis over CONUS and the Gulf Stream highlighted the tendency for NCAR and CNRM atmosphereonly simulations (NCAR-CESM2 AMIP and CNRM-CM6.1 AMIP) and ERA5 to be more consistent with observations in regions susceptible to convection, though NCAR-CESM2 AMIP and CNRM-CM6.1 AMIP still produced large discrepancies to observations (Fig. 1). The CONUS analysis also demonstrated IMERG's skill in representing the diurnal cycle of precipitation in this region, including the eastward propagation in the time of maximum precipitation from the Rockies, and its suitability for use in detailed model evaluation due to its general agreement with gauge-adjusted ground-based radar observations from MRMS. However, IMERG can exhibit some localized biases that can affect model evaluation, such as its underestimation of precipitation over the Rockies (which is larger than NCAR-CESM2 AMIP, CNRM-CM6.1 AMIP, and ERA5 underestimates) and across central CONUS, and its 3-h advance of the peak in east Great Plains precipitation, which may be due to a bias in PMW observations toward the leading convective component of MCSs (Sungmin and Kirstetter 2018).

The analysis also provided the first evaluation of the GPM Core Observatory's DPR in capturing the diurnal cycle of precipitation over CONUS. When fit by a harmonic function with only seven boreal summers of sampling, the DPR tends to outperform IMERG, NCAR-CESM2 AMIP, CNRM-CM6.1 AMIP, and ERA5 in representing the precipitation mean over the Rockies and the central United States, though is erratic in representing the normalized amplitude and time of maximum by region. However, the DPR typically better represents the time of maximum than multiple decades of simulations from NCAR-CESM2 AMIP, CNRM-CM6.1 AMIP, and ERA5. With more years of sampling, it may be possible to use the DPR as a spaceborne reference for the diurnal cycle.

The subsequent global analysis findings include the following:

1) IMERG, ERA5, NCAR, and CNRM simulations agree on the global mean precipitation for boreal summer $\left(60^{\circ} \mathrm{N}-\mathrm{S}\right.$; $\sim 3.2 \mathrm{~mm} \mathrm{day}^{-1}$ ), and the global distribution of precipitation, though disagree significantly at the regional scale (Figs. 2 and 3). Key regional discrepancies include ERA5, NCAR, and CNRM exceeding observed precipitation over drier regions of subtropical/tropical oceans, and the Himalayas, the Andes, and the Rockies; model exceedance in mountainous regions may be due to low IMERG biases, however. Low precipitation biases from IMERG in the South Atlantic and Indian Oceans $\left(45^{\circ}-60^{\circ} \mathrm{S}\right)$ are also identified.

2) The diurnal cycle of precipitation is broadly consistent between coupled, atmosphere-only and high-resolution versions of the CNRM model, and between coupled and atmosphere-only versions of the NCAR model, though differs between these models (Figs. $3 \mathrm{a}$ and $5 \mathrm{a}$, and also Fig. S4 in the online supplemental material). The following NCAR and CNRM global results are derived from atmosphereonly simulations (NCAR-CESM2 AMIP and CNRM-CM6.1 AMIP, respectively), although variations (if any) with coupled or high-resolution simulations are typically small.

3) IMERG identifies diurnal precipitation amplitudes (normalized by the mean) to be greater over land $(26 \%-134 \%$; 5th-95th percentile) than over ocean $(14 \%-66 \%)$, with a significant reduction south of $30^{\circ} \mathrm{S}$ over ocean (Figs. 4 and 5). Furthermore, IMERG observes normalized diurnal variations in precipitation to be greater in the wettest regions on Earth than in regions that receive average precipitation. Also, IMERG observes precipitation to peak over land at 1400-2100 LST, and 2100-0600 LST close to mountainous regions (Rockies, Andes, Himalayas) and regions with varying terrain (central Africa, northeastern South America; Figs. 6 and 7). Over ocean, IMERG observes precipitation to peak at 0000-1200 LST, with peaks closer to midday in coastal regions. No distinctive variation in the time of maximum as a function of mean precipitation amount is identified over land, while wetter ocean regions experience maximum precipitation later in the morning.

4) In terms of diurnal normalized amplitudes over land, ERA5 overestimates across the tropics and Northern Hemisphere, CNRM overestimates over the tropics and central Asia, and NCAR underestimates everywhere (Figs. 4 and 5). Over ocean, ERA5, NCAR, and CNRM underestimate normalized amplitudes everywhere. ERA5's global distribution of normalized amplitudes (20\%-185\% over land; $6 \%-50 \%$ over ocean) compares better to IMERG than the selected CMIP6 simulations (by comparison of land/ocean medians).

5) NCAR, ERA5, and CNRM simulate precipitation over land earlier than observed by IMERG, with average differences in the time of maximum of $-1,-2$, and $-4 \mathrm{~h}$, respectively (Figs. 6 and 7). Precipitation peaks between 1000 and 2100 LST for NCAR (2200-0600 LST over central Africa and the Eurasian Plateau), 0800 and 1600 LST for CNRM (1900-0200 LST over tropical coastlines and the Eurasian Plateau), and 1100 and 1800 LST for ERA5 (0000-0400 LST over the Rockies and the Andes). NCAR produces the poorest spatial distribution of diurnal phases over flatter land, whereas ERA5 exhibits some skill in capturing mountainous nocturnal propagation unlike NCAR and CNRM.

6) ERA5, NCAR, and CNRM better capture the time of maximum precipitation over ocean than over land; NCAR matches the IMERG phase on average, while ERA5 and CNRM have an average phase difference to IMERG of $-1 \mathrm{~h}$ (Figs. 6 and 7). All simulate oceanic precipitation to peak between 0000 and 1100 LST, similar to IMERG, although they fail to capture the observed bimodal distribution of phases with peaks at 0100 and 0600 LST.

7) Interannual variability (IAV) in the precipitation mean and normalized amplitude is small on average for IMERG, NCAR, CNRM, and ERA5 ( $<42 \%$ of the multidecade 
parameter; Fig. 8). However, IMERG observes the IAV in the time of maximum to be highly variable. IMERG suggests that the diurnal phase is only consistent from year to year (IAV $<2 \mathrm{~h}$ ) over Central America, southeastern United States, the Rockies, southeastern Asia, and eastern central Africa, where the diurnal amplitude (from the multidecade sample) is similar in magnitude to the diurnal precipitation mean ( $>105 \%$ of the mean; Fig. 9). ERA5's representation of the diurnal cycle is too simplified, simulating year-to-year consistency in diurnal phases across land and ocean regions more than observed (i.e., where the amplitude typically exceeds $56 \%$ of the precipitation mean).

The convection-parameterized NCAR model is shown to exhibit good skill in capturing the global distribution of diurnal time of maximum and may benefit from some improvements to better represent the spatial variation in phases. NCAR, CNRM, and ERA5 are highlighted to have difficulty with simulating precipitation later in the day, and with accurately capturing nocturnal peaks in precipitation in mountainous and varying terrain regions. Xie et al. (2019) suggested that these deficiencies could be addressed by limiting the onset of convection (to better capture the late afternoon maxima in precipitation) and enabling convection to occur above the boundary layer (which enables nocturnal peaks in certain regions). ERA5 simulates nocturnal precipitation peaks over the Rocky Mountains and the Andes (unlike NCAR and CNRM), potentially due to the assimilation of 6-hourly CONUS precipitation retrievals and satellite brightness temperature observations; however, ERA5 fails to produce the observed eastward phase propagation in these regions and may benefit from assimilating highertemporal-resolution precipitation retrievals. Systematic underestimates in diurnal normalized amplitude over ocean by NCAR, CNRM, and ERA5, and overestimates by ERA5 over land are further factors to be addressed for improving model/reanalysis realism.

IMERG validation is of paramount importance for model evaluation studies. The IMERG-MRMS comparison, and other preceding validation studies (e.g., Tan et al. 2016; Dezfuli et al. 2017; Sungmin and Kirstetter 2018; Tan et al. 2019b; Tang et al. 2020), demonstrate IMERG's capability to represent precipitation, although they also identify its pitfalls. Further validation studies are required to assess IMERG's skill in capturing the diurnal cycle across regions other than CONUS, Africa, and China, and to identify biases that could be misinterpreted as model inaccuracies.

There are many challenges to determining the diurnal cycle from a single low-Earth-orbit satellite (including spatially inconsistent sampling that can introduce noise into the cycle at fine scales; Negri et al. 2002); the results have shown that even 7 years of DPR observations are insufficient to properly sample the diurnal cycle. A constellation of satellites can improve the spatial coverage and revisit time of precipitation observations (Hou et al. 2014); the augmented satellite constellation coverage from IMERG has strong skill in capturing the diurnal cycle over CONUS, and multiple decades of consistent coverage has enabled discovery of the large yearly fluctuations in the time of precipitation maximum. Satellite constellation challenges include potentially observing maximum precipitation later than at the surface since their PMW and IR sensors respectively sense cloud tops and hydrometeors aloft (Dai et al. 2007), and a lack of subdaily calibration in their precipitation products; however, phase lags may be reduced with enhanced PMW contribution in such products (Tan et al. 2019a). Continuous operations and renewal and deployment of GPMlike constellations, including multiwavelength Doppler radars (Battaglia et al.2020b), are of paramount importance for diurnal cycle studies and the evaluation of models. This should be considered in the current studies in preparation of the NASA Aerosol, Cloud, Convection and Precipitation (ACCP) mission.

The results of this study have many potential impacts. Highlighted deficiencies in the state-of-the-art models and reanalysis need to be tackled to improve their realism, especially in light of the extensive use of CMIP6 models for simulating future climate change scenarios (Eyring et al. 2016). Future studies could consider further ground-based validation of the diurnal cycle of precipitation from IMERG, CMIP6, and ERA5 over different locations. Other studies could further investigate the interannual variability in the diurnal cycle and the impact of IMERG's passive microwave morphing scheme on this variability.

Acknowledgments. Daniel Watters was funded by a Natural Environment Research Council studentship awarded through the Central England NERC Training Alliance (CENTA; Grant NE/L002493/1) and by the University of Leicester. Alessandro Battaglia's work was supported by the European Space Agency under the activity "RainCast" (Contract 4000125959/18/NL/NA). Richard P. Allan was funded by the National Centre for Earth Observation Grant NE/RO16518/1. The authors thank three anonymous reviewers for their helpful comments and recommendations, which greatly helped to improve the paper. The authors thank Kamil Mroz for suggesting the inclusion of MRMS in the CONUS analysis and for help with accessing the MRMS files. The version-6B level-3 IMERG data and the version-6A level-2 DPR data were provided by the NASA/Goddard Space Flight Center and PPS, which develop and compute the data products as a contribution to GPM, and are archived at the NASA GES DISC. The authors acknowledge the World Climate Research Programme, which, through its Working Group on Coupled Modelling, coordinated and promoted CMIP6. The authors thank the climate modeling groups for producing and making available their model output, the Earth System Grid Federation (ESGF) for archiving the data and providing access, and the multiple funding agencies who support CMIP6 and ESGF. This publication contains Copernicus Climate Change Service information (2020); neither the European Commission nor ECMWF is responsible for any use that may be made of the Copernicus information or data it contains. This research used the SPECTRE High Performance Computing Facility at the University of Leicester.

Data availability statement. All data products are freely available from their respective data sources listed in Table 1 . The NCAR data are available under the CC BY-SA 4.0 license 
(https://creativecommons.org/licenses/by-sa/4.0/), and the CNRMCERFACS data are available under the CC BY-NC-SA 4.0 license (https://creativecommons.org/licenses/by-nc-sa/4.0/).

\section{REFERENCES}

Adler, R. F., and Coauthors, 2018: The Global Precipitation Climatology Project (GPCP) monthly analysis (new version 2.3) and a review of 2017 global precipitation. Atmosphere, 9 , 138, https://doi.org/10.3390/atmos9040138.

Allan, R. P., and Coauthors, 2020: Advances in understanding large-scale responses of the water cycle to climate change. Ann. N. Y. Acad. Sci., 1472, 49-75, https://doi.org/10.1111/ nyas.14337.

Battaglia, A., K. Mroz, D. Watters, and F. Ardhuin, 2020a: GPMderived climatology of attenuation due to clouds and precipitation at Ka-band. IEEE Trans. Geosci. Remote Sens., 58, 1812-1820, https://doi.org/10.1109/TGRS.2019.2949052.

— , and Coauthors, 2020b: Spaceborne cloud and precipitation radars: Status, challenges, and ways forward. Rev. Geophys., 58, e2019RG000686, https://doi.org/10.1029/2019RG000686.

Bechtold, P., N. Semane, P. Lopez, J.-P. Chaboureau, A. Beljaars, and N. Bormann, 2014: Representing equilibrium and nonequilibrium convection in large-scale models. J. Atmos. Sci., 71, 734-753, https://doi.org/10.1175/JAS-D-13-0163.1.

Berg, W., and Coauthors, 2016: Intercalibration of the GPM microwave radiometer constellation. J. Atmos. Oceanic Technol., 33, 2639-2654, https://doi.org/10.1175/JTECH-D-16-0100.1.

Betts, A. K., and C. Jakob, 2002: Evaluation of the diurnal cycle of precipitation, surface thermodynamics, and surface fluxes in the ECMWF model using LBA data. J. Geophys. Res., 107, 8045, https://doi.org/10.1029/2001JD000427.

Chen, M., R. E. Dickinson, X. Zeng, and A. N. Hahmann, 1996: Comparison of precipitation observed over the continental United States to that simulated by a climate model. J. Climate, 9, 2233-2249, https://doi.org/10.1175/1520-0442(1996)009<2233: COPOOT $>2.0 . \mathrm{CO} ; 2$.

Covey, C., P. J. Gleckler, C. Doutriaux, D. N. Williams, A. Dai, J. Fasullo, K. Trenberth, and A. Berg, 2016: Metrics for the diurnal cycle of precipitation: Toward routine benchmarks for climate models. J. Climate, 29, 4461-4471, https://doi.org/ 10.1175/JCLI-D-15-0664.1.

Dai, A., 2001: Global precipitation and thunderstorm frequencies. Part II: Diurnal variations. J. Climate, 14, 1112-1128, https://doi.org/ 10.1175/1520-0442(2001)014<1112:GPATFP $>2.0 . C O ; 2$.

- 2006: Precipitation characteristics in eighteen coupled climate models. J. Climate, 19, 4605-4630, https://doi.org/10.1175/ JCLI3884.1.

— , and K. E. Trenberth, 2004: The diurnal cycle and its depiction in the Community Climate System Model. J. Climate, 17, 930-951, https:// doi.org/10.1175/1520-0442(2004)017<0930:TDCAID>2.0.CO;2.

— , F. Giorgi, and K. E. Trenberth, 1999: Observed and modelsimulated diurnal cycles of precipitation over the contiguous United States. J. Geophys. Res., 104, 6377-6402, https:// doi.org/10.1029/98JD02720.

__, X. Lin, and K.-L. Hsu, 2007: The frequency, intensity, and diurnal cycle of precipitation in surface and satellite observations over low-and mid-latitudes. Climate Dyn., 29, 727-744, https://doi.org/10.1007/s00382-007-0260-y.

Danabasoglu, G., 2019a: NCAR CESM2 model output prepared for CMIP6 CMIP AMIP, version 20200428. Subset used: JuneAugust 1979-2008, Earth System Grid Federation, accessed 28 April 2020, https://doi.org/10.22033/ESGF/CMIP6.7522.
- 2019b: NCAR CESM2 model output prepared for CMIP6 CMIP historical, version 20200428. Subset used: June-August 1979-2008, Earth System Grid Federation, accessed 28 April 2020, https://doi.org/10.22033/ESGF/CMIP6.7627.

— version 2 (CESM2). J. Adv. Model. Earth Syst., 12, e2019MS001916, https://doi.org/10.1029/2019MS001916.

DeMott, C. A., D. A. Randall, and M. Khairoutdinov, 2007: Convective precipitation variability as a tool for general circulation model analysis. J. Climate, 20, 91-112, https://doi.org/ 10.1175/JCLI3991.1.

Dezfuli, A. K., C. M. Ichoku, G. J. Huffman, K. I. Mohr, J. S. Selker, N. Van De Giesen, R. Hochreutener, and F. O. Annor, 2017: Validation of IMERG precipitation in Africa. J. Hydrometeor., 18, 2817-2825, https://doi.org/10.1175/JHM-D-17-0139.1.

Dirmeyer, P. A., and Coauthors, 2012: Simulating the diurnal cycle of rainfall in global climate models: Resolution versus parameterization. Climate Dyn., 39, 399-418, https://doi.org/ 10.1007/s00382-011-1127-9.

ECMWF, 2020: Part IV: Physical processes. Operational Implementation 30 June 2020, IFS Doc. CY47R1, 228 pp., https://www.ecmwf.int/node/19748.

Eyring, V., S. Bony, G. A. Meehl, C. A. Senior, B. Stevens, R. J. Stouffer, and K. E. Taylor, 2016: Overview of the Coupled Model Intercomparison Project Phase 6 (CMIP6) experimental design and organization. Geosci. Model Dev., 9, 19371958, https://doi.org/10.5194/gmd-9-1937-2016.

Flato, G., and Coauthors, 2014: Evaluation of climate models. Climate Change 2013: The Physical Science Basis, T. F. Stocker et al., Eds., Cambridge University Press, 741-866.

Hersbach, H., and Coauthors, 2018: ERA5 hourly data on single levels from 1979 to present, version 20180614. Subset used: June-August 2000-2019, Copernicus Climate Change Service Climate Data Store, accessed 24 June 2020, https://doi.org/ 10.24381/cds.adbb2d47.

— , and Coauthors, 2020: The ERA5 global reanalysis. Quart. J. Roy. Meteor. Soc., 146, 1999-2049, https://doi.org/10.1002/ qj.3803.

Hong, Y., K.-L. Hsu, S. Sorooshian, and X. Gao, 2004: Precipitation estimation from remotely sensed imagery using an artificial neural network cloud classification system. J. Appl. Meteor., 43, 1834-1853, https://doi.org/10.1175/JAM2173.1.

Hou, A. Y., and Coauthors, 2014: The Global Precipitation Measurement Mission. Bull. Amer. Meteor. Soc., 95, 701-722, https://doi.org/10.1175/BAMS-D-13-00164.1.

Huffman, G. J., and Coauthors, 2007: The TRMM Multisatellite Precipitation Analysis (TMPA): Quasi-global, multiyear, combined-sensor precipitation estimates at fine scales. J. Hydrometeor., 8, 38-55, https://doi.org/10.1175/JHM560.1.

- , E. Stocker, D. Bolvin, E. Nelkin, and T. J., 2019a: GPM IMERG Final Precipitation L3 Half Hourly 0.1 degree $\times 0.1$ degree, version 6B. Subset used: June-August 2000-2019, GES DISC, accessed 20 April 2020, https://doi.org/10.5067/ GPM/IMERG/3B-HH/06.

—, and Coauthors, 2019b: NASA Global Precipitation Measurement (GPM) Integrated Multi-satellitE Retrievals for GPM (IMERG). Algorithm Theoretical Basis Doc., version 6, 38 pp., accessed 24 October 2020, https://pmm.nasa.gov/sites/default/ files/document_files/IMERG_ATBD_V06.pdf.

_, D. T. Bolvin, E. J. Nelkin, E. F. Stocker, and J. Tan, 2020a: V06 IMERG Release Notes. NASA Tech. Rep., 15 pp., accessed 16 October 2020, https:/gpm.nasa.gov/sites/default/ files/2020-10/IMERG_V06_release_notes_201006_0.pdf. 
— , and Coauthors, 2020b: Integrated Multi-satellite Retrievals for the Global Precipitation Measurement (GPM) Mission (IMERG). Satellite Precipitation Measurement, Springer, 343-353.

Iguchi, T., 2020: Dual-Frequency Precipitation Radar (DPR) on the Global Precipitation Measurement (GPM) Mission's Core Observatory. Satellite Precipitation Measurement, Springer, 183-192.

_ , and R. Meneghini, 2017: GPM DPR Precipitation Profile L2A 1.5 hours $5 \mathrm{~km}$, version 6A. Subset used: June-August 2014-2020, GES DISC, accessed 8 September 2020, https:// doi.org/10.5067/GPM/DPR/GPM/2A/06.

—_, and Coauthors, 2018: GPM/DPR Level-2. NASA Algorithm Theoretical Basis Doc., 127 pp., accessed 7 October 2020, https://pps.gsfc.nasa.gov/Documents/ATBD_DPR_201811_with_ Appendix3b.pdf.

Jammalamadaka, S. R., and A. SenGupta, 1999: Topics in Circular Statistics. Vol. 5, Multivariate Analysis, World Scientific, 336 pp., https://doi.org/10.1142/4031.

Janowiak, J. E., P. A. Arkin, and M. Morrissey, 1994: An examination of the diurnal cycle in oceanic tropical rainfall using satellite and in situ data. Mon. Wea. Rev., 122, 2296-2311, https://doi.org/10.1175/1520-0493(1994)122<2296: AEOTDC $>2.0 . \mathrm{CO} ; 2$.

Joyce, R. J., and P. Xie, 2011: Kalman filter-based CMORPH. J. Hydrometeor., 12, 1547-1563, https://doi.org/10.1175/JHMD-11-022.1.

Kidd, C., 2019: NASA Global Precipitation Measurement (GPM) Precipitation Retrieval and Profiling Scheme (PRPS). NASA Algorithm Theoretical Basis Doc., version 02-02, 18 pp., accessed 8 March 2021, https://arthurhou.pps.eosdis.nasa.gov/ Documents/20190726_SAPHIR-ATBD_V02-02.pdf.

— E. E. Dawkins, and G. Huffman, 2013: Comparison of precipitation derived from the ECMWF operational forecast model and satellite precipitation datasets. J. Hydrometeor., 14, 14631482, https://doi.org/10.1175/JHM-D-12-0182.1.

—, Y. N. Takayabu, G. M. Skofronick-Jackson, G. J. Huffman, S. A. Braun, T. Kubota, and F. J. Turk, 2020: The Global Precipitation Measurement (GPM) Mission. Satellite Precipitation Measurement, Springer, 3-23.

Kikuchi, K., and B. Wang, 2008: Diurnal precipitation regimes in the global tropics. J. Climate, 21, 2680-2696, https://doi.org/ 10.1175/2007JCLI2051.1.

Kirstetter, P.-E., W. A. Petersen, C. D. Kummerow, and D. B. Wolff, 2020: Integrated Multi-satellite Evaluation for the Global Precipitation Measurement: Impact of Precipitation Types on Spaceborne Precipitation Estimation. Satellite Precipitation Measurement, Springer, 583-608.

Kummerow, C., W. Barnes, T. Kozu, J. Shiue, and J. Simpson, 1998: The Tropical Rainfall Measuring Mission (TRMM) sensor package. J. Atmos. Oceanic Technol., 15, 809-817, https://doi.org/ 10.1175/1520-0426(1998)015<0809:TTRMMT>2.0.CO;2.

—, D. L. Randel, M. Kulie, N.-Y. Wang, R. Ferraro, S. Joseph Munchak, and V. Petkovic, 2015: The evolution of the Goddard profiling algorithm to a fully parametric scheme. J. Atmos. Oceanic Technol., 32, 2265-2280, https://doi.org/ 10.1175/JTECH-D-15-0039.1.

Liu, C., and E. J. Zipser, 2008: Diurnal cycles of precipitation, clouds, and lightning in the tropics from 9 years of TRMM observations. Geophys. Res. Lett., 35, L04819, https://doi.org/ 10.1029/2007GL032437.

Lopez, P., 2011: Direct 4D-Var assimilation of NCEP stage IV radar and gauge precipitation data at ECMWF. Mon. Wea. Rev., 139, 2098-2116, https://doi.org/10.1175/2010MWR3565.1.
Maranan, M., A. H. Fink, P. Knippertz, L. K. Amekudzi, W. A. Atiah, and M. Stengel, 2020: A process-based validation of GPM IMERG and its sources using a mesoscale rain gauge network in the West African forest zone. J. Hydrometeor., 21, 729-749, https://doi.org/10.1175/JHM-D-19-0257.1.

Minobe, S., J. H. Park, and K. S. Virts, 2020: Diurnal cycles of precipitation and lightning in the tropics observed by TRMM3G68, GSMaP, LIS, and WWLLN. J. Climate, 33, 4293-4313, https://doi.org/10.1175/JCLI-D-19-0389.1.

Navarro, A., E. García-Ortega, A. Merino, J. L. Sánchez, C. Kummerow, and F. J. Tapiador, 2019: Assessment of IMERG precipitation estimates over Europe. Remote Sens., 11, 2470, https://doi.org/10.3390/rs11212470.

Negri, A. J., T. L. Bell, and L. Xu, 2002: Sampling of the diurnal cycle of precipitation using TRMM. J. Atmos. Oceanic Technol., 19, 1333-1344, https://doi.org/10.1175/1520-0426(2002)019<1333: SOTDCO $>2.0 . \mathrm{CO} ; 2$.

Nesbitt, S. W., and E. J. Zipser, 2003: The diurnal cycle of rainfall and convective intensity according to three years of TRMM measurements. J. Climate, 16, 1456-1475, https://doi.org/ 10.1175/1520-0442-16.10.1456.

NOAA, 2020: Multi-Radar Multi-Sensor Hourly Quantitative Precipitation Estimation with Gauge Correction. Subset used: June-August 2015-2020, Iowa State University, accessed 1 September 2020, https://mtarchive.geol.iastate.edu/.

Olson, W. S., 2018: GPM Combined Radar-Radiometer Precipitation. NASA Algorithm Theoretical Basis Doc., version 5, 68 pp., accessed 25 October 2020, https:/gpm.nasa.gov/sites/default/files/ 2020-05/Combined_algorithm_ATBD.V05.pdf.

Pearson, K. J., G. M. S. Lister, C. E. Birch, R. P. Allan, R. J. Hogan, and S. J. Woolnough, 2014: Modelling the diurnal cycle of tropical convection across the 'grey zone.' Quart. J. Roy. Meteor. Soc., 140, 491-499, https://doi.org/10.1002/qj.2145.

Petersen, W. A., P.-E. Kirstetter, J. Wang, D. B. Wolff, and A. Tokay, 2020: The GPM Ground Validation Program. Satellite Precipitation Measurement, Springer, 471-502.

Ramsauer, T., T. Weiß, and P. Marzahn, 2018: Comparison of the GPM IMERG final precipitation product to RADOLAN weather radar data over the topographically and climatically diverse Germany. Remote Sens., 10, 2029, https://doi.org/ 10.3390/rs10122029.

Randall, D. A., and Coauthors, 2007: Climate models and their evaluation. Climate Change 2007: The Physical Science Basis, S. Solomon et al., Eds., Cambridge University Press, 589-662.

Rosa, D., and W. Collins, 2013: A case study of subdaily simulated and observed continental convective precipitation: CMIP5 and multiscale global climate models comparison. Geophys. Res. Lett., 40, 5999-6003, https://doi.org/10.1002/2013GL057987.

Scaff, L., A. F. Prein, Y. Li, C. Liu, R. Rasmussen, and K. Ikeda, 2020: Simulating the convective precipitation diurnal cycle in North America's current and future climate. Climate Dyn., 55, 369-382, https://doi.org/10.1007/s00382-019-04754-9.

Schneider, U., A. Becker, P. Finger, A. Meyer-Christoffer, M. Ziese, and B. Rudolf, 2014: GPCC's new land surface precipitation climatology based on quality-controlled in situ data and its role in quantifying the global water cycle. Theor. Appl. Climatol., 115, 15-40, https://doi.org/10.1007/s00704013-0860-x.

Séférian, R., 2018: CNRM-CERFACS CNRM-ESM2-1 model output prepared for CMIP6 CMIP AMIP, version 20191021. Subset used: June-August 1979-2008, Earth System Grid Federation, accessed 21 October 2019, https://doi.org/10.22033/ ESGF/CMIP6.3924. 
— , and Coauthors, 2019: Evaluation of CNRM Earth System Model, CNRM-ESM2-1: Role of Earth system processes in present-day and future climate. J. Adv. Model. Earth Syst., 11, 4182-4227, https://doi.org/10.1029/2019MS001791.

Simpson, J., C. Kummerow, W.-K. Tao, and R. F. Adler, 1996: On the Tropical Rainfall Measuring Mission (TRMM). Meteor. Atmos. Phys., 60, 19-36, https://doi.org/10.1007/BF01029783.

Skofronick-Jackson, G., and Coauthors, 2017: The Global Precipitation Measurement (GPM) mission for science and society. Bull. Amer. Meteor. Soc., 98, 1679-1695, https:// doi.org/10.1175/BAMS-D-15-00306.1.

—, D. Kirschbaum, W. Petersen, G. Huffman, C. Kidd, E. Stocker, and R. Kakar, 2018: The Global Precipitation Measurement (GPM) mission's scientific achievements and societal contributions: Reviewing four years of advanced rain and snow observations. Quart. J. Roy. Meteor. Soc., 144, 27-48, https://doi.org/10.1002/qj.3313.

Stephens, G. L., and Coauthors, 2010: Dreary state of precipitation in global models. J. Geophys. Res., 115, D24211, https:// doi.org/10.1029/2010JD014532.

_- and Coauthors, 2012: An update on Earth's energy balance in light of the latest global observations. Nat. Geosci., 5, 691-696, https://doi.org/10.1038/ngeo1580.

Sungmin, O., and P. Kirstetter, 2018: Evaluation of diurnal variation of GPM IMERG-derived summer precipitation over the contiguous US using MRMS data. Quart. J. Roy. Meteor. Soc., 144, 270-281, https://doi.org/10.1002/qj.3218.

Tan, J., W. A. Petersen, and A. Tokay, 2016: A novel approach to identify sources of errors in IMERG for GPM ground validation. J. Hydrometeor., 17, 2477-2491, https://doi.org/10.1175/ JHM-D-16-0079.1.

— , G. J. Huffman, D. T. Bolvin, and E. J. Nelkin, 2019a: Diurnal cycle of IMERG V06 precipitation. Geophys. Res. Lett., 46, 13 584-13 592, https://doi.org/10.1029/2019GL085395.

,,,--- and,$- 2019 \mathrm{~b}$ : IMERG V06: Changes to the morphing algorithm. J. Atmos. Oceanic Technol., 36, 24712482, https://doi.org/10.1175/JTECH-D-19-0114.1.

Tang, G., M. P. Clark, S. M. Papalexiou, Z. Ma, and Y. Hong, 2020: Have satellite precipitation products improved over last two decades? A comprehensive comparison of GPM IMERG with nine satellite and reanalysis datasets. Remote Sens. Environ., 240, 111697, https://doi.org/10.1016/j.rse.2020.111697.

Tapiador, F. J., R. Roca, A. Del Genio, B. Dewitte, W. Petersen, and F. Zhang, 2019: Is precipitation a good metric for model performance? Bull. Amer. Meteor. Soc., 100, 223-233, https:// doi.org/10.1175/BAMS-D-17-0218.1.

—- A. Navarro, E. García-Ortega, A. Merino, J. L. Sánchez, C. Marcos, and C. Kummerow, 2020: The contribution of rain gauges in the calibration of the IMERG product: Results from the first validation over Spain. J. Hydrometeor., 21, 161-182, https://doi.org/10.1175/JHM-D-19-0116.1.

Trenberth, K. E., A. Dai, R. M. Rasmussen, and D. B. Parsons, 2003: The changing character of precipitation. Bull. Amer. Meteor. Soc., 84, 1205-1218, https://doi.org/10.1175/BAMS84-9-1205.
— , Y. Zhang, and M. Gehne, 2017: Intermittency in precipitation: Duration, frequency, intensity, and amounts using hourly data. J. Hydrometeor., 18, 1393-1412, https://doi.org/10.1175/ JHM-D-16-0263.1.

UCAR, 2020: Model physics. CAM6 Scientific Guide, accessed 16 September 2020, https://ncar.github.io/CAM/doc/build/ html/cam6_scientific_guide/physics.html\#deep-convection.

Voldoire, A., 2018a: CMIP6 simulations of the CNRM-CERFACS based on CNRM-CM6-1 model for CMIP experiment historical, version 20200428. Subset used: June-August 1979-2008, Earth System Grid Federation, accessed 28 April 2020, https:// doi.org/10.22033/ESGF/CMIP6.4066.

- 2018b: CNRM-CERFACS CNRM-CM6-1 model output prepared for CMIP6 CMIP AMIP, version 20200603. Subset used: June-August 1979-2008, Earth System Grid Federation, accessed 3 June 2020, https://doi.org/10.22033/ ESGF/CMIP6.3922.

—, 2019: CNRM-CERFACS CNRM-CM6-1-HR model output prepared for CMIP6 CMIP historical, version 20200428. Subset used: June-August 1979-2008, Earth System Grid Federation, accessed 28 April 2020, https://doi.org/10.22033/ ESGF/CMIP6.4066.

—- and Coauthors, 2019: Evaluation of CMIP6 deck experiments with CNRM-CM6-1. J. Adv. Model. Earth Syst., 11, 21772213, https://doi.org/10.1029/2019MS001683.

Wallace, J. M., 1975: Diurnal variations in precipitation and thunderstorm frequency over the conterminous United States. Mon. Wea. Rev., 103, 406-419, https://doi.org/10.1175/15200493(1975)103<0406:DVIPAT>2.0.CO;2.

Watters, D., and A. Battaglia, 2019: The summertime diurnal cycle of precipitation derived from IMERG. Remote Sens., 11, 1781, https://doi.org/10.3390/rs11151781.

— Measurement mission-Part I: New frontiers in precipitation. Weather, 76, 41-44, https://doi.org/10.1002/wea.3865.

- , and $-2020 \mathrm{~b}$ : The NASA-JAXA Global Precipitation Measurement mission-Part II: New frontiers in precipitation science. Weather, 76, 52-56, https://doi.org/10.1002/wea.3869.

WCRP, 2020a: CNRM-ESM2-1: Atmosphere-Turbulence convection. WCRP, accessed 23 September 2020, https://explore.esdoc.org/cmip6/models/cnrm-cerfacs/cnrm-esm2-1.

- 2020b: WCRP-CMIP CMIP6 CVs version: 6.2.54.5. Accessed 3 December 2020, https://wcrp-cmip.github.io/CMIP6_CVs/ docs/CMIP6_source_id.html.

Xie, S., and Coauthors, 2019: Improved diurnal cycle of precipitation in E3SM with a revised convective triggering function. J. Adv. Model. Earth Syst., 11, 2290-2310, https://doi.org/ 10.1029/2019MS001702.

Yang, G.-Y., and J. Slingo, 2001: The diurnal cycle in the tropics. Mon. Wea. Rev., 129, 784-801, https://doi.org/10.1175/15200493(2001)129<0784:TDCITT>2.0.CO;2.

Zhang, J., and Coauthors, 2016: Multi-Radar Multi-Sensor (MRMS) quantitative precipitation estimation: Initial operating capabilities. Bull. Amer. Meteor. Soc., 97, 621-638, https://doi.org/10.1175/BAMS-D-14-00174.1. 